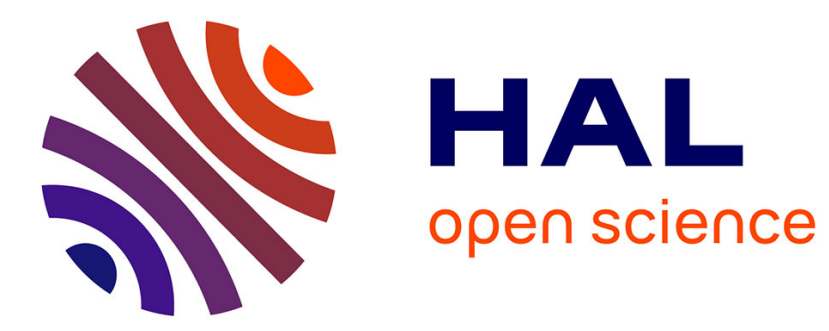

\title{
Modelling and flexible predictive control of building space-heating demand in district heating systems
}

Nadine Aoun, Roland Bavière, Mathieu Vallee, Antoine Aurousseau, Guillaume Sandou

\section{- To cite this version:}

Nadine Aoun, Roland Bavière, Mathieu Vallee, Antoine Aurousseau, Guillaume Sandou. Modelling and flexible predictive control of building space-heating demand in district heating systems. Energy, 2019, 188, 10.1016/j.energy.2019.116042 . hal-02861035

\section{HAL Id: hal-02861035 \\ https://hal-centralesupelec.archives-ouvertes.fr/hal-02861035}

Submitted on 8 Jun 2020

HAL is a multi-disciplinary open access archive for the deposit and dissemination of scientific research documents, whether they are published or not. The documents may come from teaching and research institutions in France or abroad, or from public or private research centers.
L'archive ouverte pluridisciplinaire HAL, est destinée au dépôt et à la diffusion de documents scientifiques de niveau recherche, publiés ou non, émanant des établissements d'enseignement et de recherche français ou étrangers, des laboratoires publics ou privés. 


\title{
Modelling and flexible control of building space-heating demand in district heating systems
}

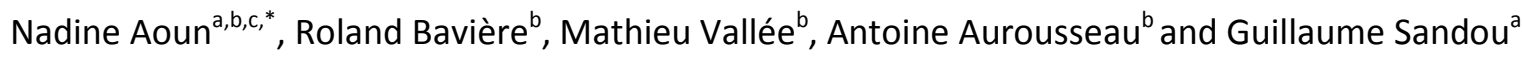 \\ ${ }^{a}$ L2S, CentraleSupélec, CNRS, Université Paris-Sud, Université Paris-Saclay, 91190 Gif-sur-Yvette, France \\ ${ }^{b}$ CEA, LITEN, 17 rue des Martyrs, F-38054 Grenoble, France \\ ${ }^{\mathrm{c}}$ ADEME, 20 Avenue du Grésillé, 49000 Angers, France \\ *Corresponding author, nadine.aoun@cea.fr, (+33) 479792148
}

\begin{abstract}
This paper presents and demonstrates, by numerical simulation, a mixed-integer linear programming (MILP)-based Model Predictive Control (MPC) strategy for space-heating demand in buildings connected to a district heating system. The proposed MPC deals with space-heating demand with extended flexibility. It exploits thermal inertia, inherently present in the building and its heating system, to optimally plan space-heating load in anticipation of weather conditions and energy cost variations. MPC is based on a reliable Reduced-Order Model (ROM). Heating circuit and internal mass are carefully modelled within the ROM structure since these elements can be used for short-term heat storage and therefore play an important role in demand-side management. As for the model parameters identification, training data is restricted to non-intrusive, easily accessible measurements available at the substation level. The model identification approach and control strategy are applied to a well-insulated radiator-heated case-study building simulator developed in Modelica. Results show that the proposed ROM is reliable enough for an MPC application. Compared to conventional weather-compensation control, flexible MILP-based MPC proved to be cost-efficient, while preserving a decent indoor thermal comfort level.
\end{abstract}

Key-words: Building thermal dynamic simulation; Lumped capacitance model; Mixed-integer linear program; Model predictive control; Parameters identification; Reduced order building

model. 


\section{Acronyms}

$\begin{array}{ll}\text { DHS } & \text { District Heating System } \\ \text { DSM } & \text { Demand Side Management } \\ \text { FMU } & \text { Functional Mock-up Unit } \\ \text { MILP } & \text { Mixed-Integer Linear Programming } \\ \text { MPC } & \text { Model Predictive Control } \\ \text { RC } & \text { Resistance-Capacitance } \\ \text { ROM } & \text { Reduced-Order Model } \\ \text { WC } & \text { Weather-Compensation }\end{array}$

Latin letters

$$
\begin{array}{clc}
c^{\text {energy }} & \text { Energy cost } & (€ / J) \\
c_{p} & \text { Specific heat capacity of water } & (\mathrm{J} /(\mathrm{Kg} \cdot \mathrm{K})) \\
C & \text { Thermal capacitance } & (\mathrm{J} / \mathrm{K}) \\
k^{s} & \text { Solar aperture surface area } & \left(\mathrm{m}^{2}\right) \\
G^{p} & \text { Proportional gain for temperature regulation } & (1 / \mathrm{K}) \\
H^{2} & \text { Receding horizon in the MPC } & (\mathrm{hours}) \\
N_{d i s c} & \text { Number of discretized parts in an interval } & (-) \\
N_{s t e p} & \text { Number of time steps in the MPC prediction horizon } & (-) \\
\dot{m} & \text { Space-heating water mass flowrate } & (\mathrm{kg} / \mathrm{s}) \\
p & \text { Penalty cost for discomfort } & (€ /(\mathrm{K} \cdot \mathrm{S})) \\
T & \text { Temperature } & (\mathrm{K}) \\
U_{e q}, \widehat{U}_{e q} & \text { Building equivalent thermal transmittance coefficients } & (\mathrm{days})
\end{array}
$$

\section{Greek letters}

$\alpha, \beta, \delta, \rho, \omega \quad$ MILP auxiliary variables

$\Delta t \quad$ Time step

$\Delta T \quad$ Temperature difference

$\varepsilon^{\text {comf }} \quad$ Flexible temperature variation limit within the thermal comfort zone 


\section{Superscripts}

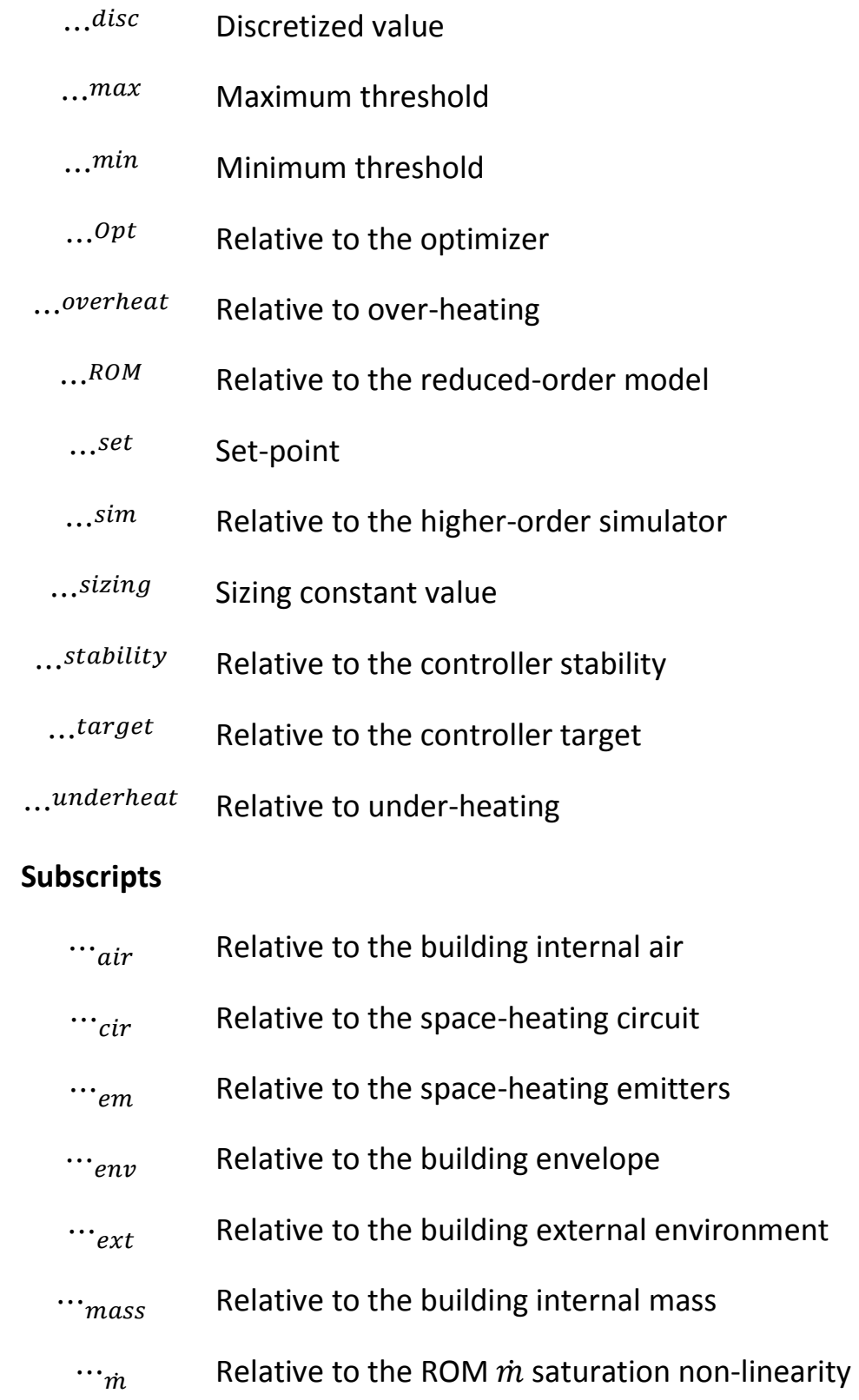

\section{Subscripts}

... $_{\text {air }} \quad$ Relative to the building internal air

$\cdots_{c i r} \quad$ Relative to the space-heating circuit

$\cdots_{\mathrm{em}} \quad$ Relative to the space-heating emitters

$\cdots_{\text {env }} \quad$ Relative to the building envelope

$\cdots_{\text {ext }} \quad$ Relative to the building external environment

${ }^{\cdots}$ mass $\quad$ Relative to the building internal mass

$\cdots_{\dot{m}} \quad$ Relative to the ROM $\dot{m}$ saturation non-linearity 
... ${ }_{M P C} \quad$ Relative to the MPC controller

$\cdots_{N L} \quad$ Relative to the ROM bilinear non-linearity

$\cdots_{S S T} \quad$ Relative to the district heating substation

' target Relative to the MPC controller target

$\cdots_{W C} \quad$ Relative to the WC controller

$\cdots_{\Phi} \quad$ Relative to the ROM $\Phi_{S S T}$ saturation non-linearity

\section{Operators}

$\llbracket X \rrbracket_{a}^{b} \quad$ Bounded value of $X$, between $a$ and $b$

$X^{*} \quad$ Unknown parameter to be identified

$\bar{X} \quad$ Arithmetic mean 


\section{Introduction}

\subsection{Motivation}

Space-heating and domestic hot water consumption account for roughly $70 \%$ of the total energy used in the residential and commercial sector [1], which itself consumes around $45 \%$ of the final energy produced in France [2]. These numbers hint that small individual energy savings in this sector might have great impacts at a country level and that, if the Paris Agreement was to be fulfilled, the transition towards smart and sustainable heating systems would be fundamental.

District heating has long been known as an economically and environmentally efficient heating mode. It is particularly praised over individual heating for its ability to integrate any available heat source. Recent research in this field's leading countries stresses that District Heating Systems (DHSs) have genuinely an important role to play in the future of sustainable energy systems and demonstrates how their expansion could allow conversion into up to $100 \%$ renewable energy resources by less than 50 years in Denmark [3,4]. Yet, in order to reach such goals, current DHSs must evolve towards their $4^{\text {th }}$ Generation [5]. Improvements encompass reforming metering and pricing policies, enhancing the layout and reducing losses in the grids, lowering supply and return temperatures, reinforcing intermittent renewable energy (solar and geothermal) and lowtemperature waste heat penetration, introducing large-scale heat pumps in combined heat and power plants, establishing synergies between various energy systems typically electrical, thermal and gas, and eventually developing intelligent control strategies to optimally manage all the components in the system. The tasks are quite challenging [6], the research community is truly active on prospective tracks and still, further research is needed for the practical implementation of the proposed solutions [7].

This work involves implementing advanced control strategies in DHSs that can be done, separately or coupled, at three levels: production, distribution and demand. In this paper, the main focus is on flexible control of space-heating demand.

\subsection{Towards smart control strategies}

Currently, in most DHSs, space-heating demand is managed using Weather-Compensation (WC) controllers at the substation level. In order to insure a given indoor set-point temperature, a WC controller uses static heating curves to regulate the inlet water temperature of the building heating circuit (the secondary side of the substation) as a linear function of the outdoor temperature. Inside the buildings, thermostatic valves (proportional control) are often installed and regulate the heating water flow across the heat emitters (radiators or floor heating) to maintain the indoor air temperature close to its set-point. This control mode is purely reactive and lacks flexibility. In fact, it does not consider making smart decisions such as strategically setting-back the heating power to exploit the intrinsic thermal inertia of the building and its heating system. Indeed future energy systems call for smart control strategies which deal with space-heating with further flexibility [8-10]. Concretely, the DHS operator would use controllers that allow applying Demand-Side Management (DSM) measures and optimally modulating the heat supply from the substation in anticipation of weather conditions and energy costs. Nevertheless, consumers' comfort shall not be jeopardized. In order to ensure this requirement, optimal control strategies rely on building models with the ability to predict the evolution of end-users thermal comfort. These models are used within a Model Predictive Control (MPC) strategy, along with weather and energy cost forecasts, to solve a control optimization problem over a future horizon and apply its output on the building system. The suitability of MPC to tackle space-heating demand management has been proven both theoretically [11-13] and through real-life experiments, mostly on non-residential buildings [14-16] and hardly at a DHS scale [17]. 
Nevertheless, MPC can be quite challenging, and most studies agree that developing a reliable model is the most crucial and time-consuming part of the problem [18,19]. Generally, the process of developing a model starts by defining its structure, then setting its parameters. There exists a myriad of building model structures [20]. Those suitable for MPC applications are summarized in [21]. As for parameters setting, it is usually done either by estimation if detailed description of the building geometry and construction materials is well-known, or by identification approaches (deterministic or probabilistic) using historical data to tune the parameters, or a combination of both. So far, in the literature, parameters identification has used internal temperature measurements from sensors readily installed inside the building. This has worked at a single building level; however, these measurements are intrusive and at a DHS level their access is subject to data-protection policies, besides technical difficulties. To ease MPC implementation at a large scale, a convenient building model identification approach relying on measurements available at the substation solely is proposed in this paper. A Mixed-Integer Linear Programming (MILP) optimization problem is formulated and illustrative MPC tests based on the identified model are presented and analysed. The whole work is done by numerical simulation means.

\subsection{Paper structure}

This paper is organised as follows. The building thermal dynamic simulator is presented in Section 2. Using data generated by this simulator, a reduced-order building model structure is proposed in Section 3, together with a methodology for parameters identification. In Section 4, the space-heating optimization problem is formulated under the MILP formalism by linearizing the identified model and control tests comparing MPC to standard control strategies are analysed. Section 5 concludes the paper and gives perspectives of upcoming work. 


\section{Thermal dynamic building simulation}

\subsection{Brief description of the building simulator}

A detailed building thermal dynamic simulator is developed in Modelica language. It enables rapid prototyping of multi-stories buildings based on a zonal approach. Each floor is discretized into four thermal zones equivalent to a night zone, a day zone, a kitchen and a bathroom as depicted in Figure 1. The zones are assumed to have perfectly homogeneous air and are modelled using the MixedAir component from the Modelica Buildings library [22].

Figure 1 also shows the modelled thermal phenomena in the simulator. Thermal zones exchange heat between each other due to door opening and with the surrounding envelope by natural convection. Mono-directional thermal conduction is modelled through the envelope separating the indoor from the outdoor environment whose boundary conditions are specified in a weather file. The envelope is also subject to natural convection with the outdoors. The indoor air exchanges heat directly with the outdoors through ventilation. Direct and diffuse solar irradiation penetrates through the windows, diffuse irradiation is distributed between the internal surfaces and long-wave radiant exchanges takes place between them. A radiative heat balance is therefore established inside the zones. Furthermore, since several studies emphasized the impact of internal mass on buildings shortterm heat storage during DSM measures [23-25], we added inside each zone partition walls $\left(25 \mathrm{~kg} / \mathrm{m}^{2}\right)$ and furniture-equivalent walls respectively made out of metal $\left(25 \mathrm{~kg} / \mathrm{m}^{2}\right)$, wood/plastic $\left(25 \mathrm{~kg} / \mathrm{m}^{2}\right)$, ceramic/glass $\left(5 \mathrm{~kg} / \mathrm{m}^{2}\right)$ and light material $\left(15 \mathrm{~kg} / \mathrm{m}^{2}\right)$. These figures, expressed in mass per unit of floor area, are based on [26], a survey on the internal mass and its equivalent heat capacity found in residential and single office buildings in Denmark. These walls are subject to thermal convection, mono-directional conduction and radiative heat exchange. Each zone is heated by a radiator heating system, equipped with a thermostatic radiator valve. All radiators are connected using a dual-pipe network to a DHS substation where control actions take place. Additionally, a stochastic model of internal gain injects free heat into each zone.

A multi-storey simulator may be assembled by stacking several floors as depicted in Figure 2. All floors are identical in terms of geometry and envelope construction material, except for the ground and the top floor which are distinctive by their floor and roof construction respectively.

Interested readers may refer to the authors' previous work [27] for further details about the building simulator. 


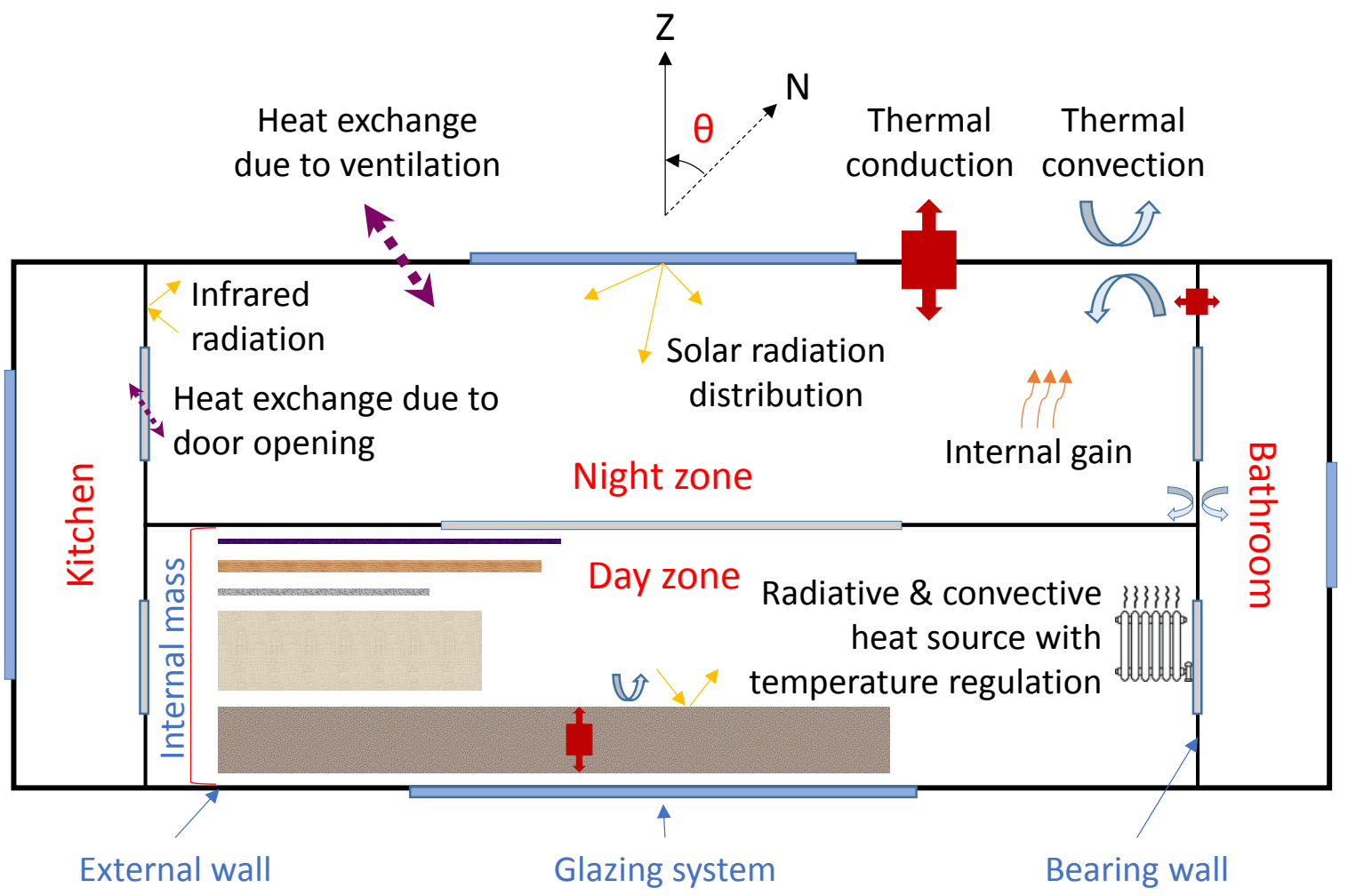

Figure 1. Schematic representation of a floor discretized into 4 equivalent thermal zones and the modelled thermal phenomena in the building simulator

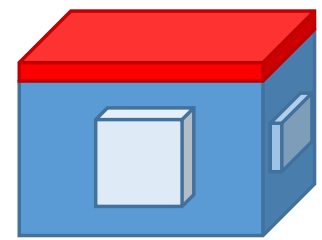

$\theta$

$\theta$

$\theta$

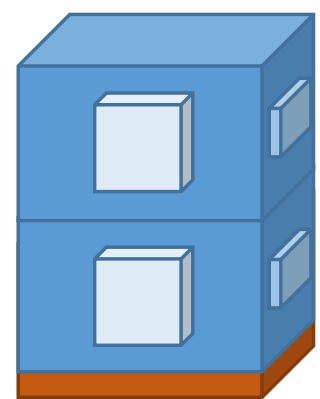

Figure 2. Schematic of a multi-stories building simulator

\subsection{Case-study building}

The building simulator is parameterized to represent a low energy consumption residential building called Le Salammbô (Figure 3) connected to a recent extension of the DHS of Grenoble - France. Le Salammbô hosts a demonstration of advanced space-heating control strategies as part of the 
European project City-zen [28]. Built in 2018, it covers a $300 \mathrm{~m}^{2}$ floor area and has 8 floors. In this study, we simulate only one floor to save on computation time. The building has an exteriorlyinsulated concrete envelope and argon-filled double-glazed windows leading to a space-heating demand of the order of $50 \mathrm{kWh} / \mathrm{m}^{2}$ for a typical meteorological year relative to Grenoble.

In this study, data generated from the building simulator will be used to identify its ROM. Then, output of the model predictive controller will be applied to the building simulator.

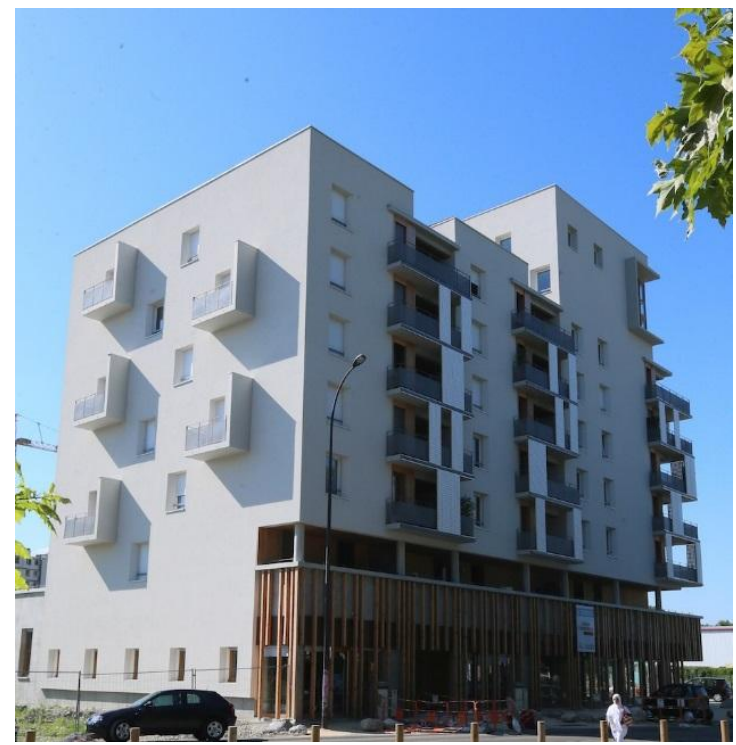

Figure 3. Photograph of the advanced control strategies demonstrator Le Salammbô - Grenoble, 2018 Photo credit: http://www.gre-mag.fr 


\section{Reduced-order building modelling}

\subsection{ROM structure}

MPC of space-heating demand relies on a reduced-order building model. As mentioned earlier, developing a ROM starts by defining its structure. Among possible structures, we gravitate towards physically interpretable models, so-called grey-box models. In fact, since limited data is available, we stay away from purely data-driven or black-box models (Artificial Neural Networks, Box-Jenkins derivatives) which usually require a massive data set. Another important requirement is a linear, or a possibly linearizable model with short computational time since the model is to be used in an online MILP optimization problem. Whereof we opted for lumped Resistance-Capacitance (RC) ROMs. Within this category, several structures have been studied in the literature to determine the model order that best captures the building thermal dynamics. Many studies concluded that a $1^{\text {st }}$ order model (all elements in the building are lumped into one temperature node) is not accurate for short time-steps prediction [29]. An improvement of the $1^{\text {st }}$ order is the $2^{\text {nd }}$ order structure. It has one capacitance for the external envelope and another for either internal air [30] or internal mass (with a capacitance-free internal air temperature) [31]. Fewer papers have considered the thermal inertia of the heating system [32].

In this work, we propose a model structure with particular attention to the internal mass and the heating system, since their respective thermal inertia is useful for short-term heat storage in the intended MPC. The resulting ROM is a conjunction of a linear $3^{\text {rd }}$ order building coupled to a nonlinear heating system model. The full modelling differential-algebraic system of equations is shown below (Eqs. Eq. (1)-Eq. (7)). Its time invariant parameters are marked with an asterisk $\left({ }^{*}\right)$ and correspond to unknown parameters that need to be identified.

$$
\begin{aligned}
& C_{\text {air }}{ }^{*} \cdot \frac{d T_{\text {air }}}{d t}=U_{[\text {air }- \text { ext }]}{ }^{*} \cdot\left(T_{\text {ext }}-T_{\text {air }}\right)+U_{[a i r-e n v]}{ }^{*} \cdot\left(T_{\text {env }}-T_{\text {air }}\right)+U_{[\text {air-mass }]}{ }^{*} \\
& \cdot\left(T_{\text {mass }}-T_{\text {air }}\right)+U_{[a i r-e m]}{ }^{*} \cdot\left(T_{e m}-T_{\text {air }}\right)+k_{\text {air }}{ }^{*} \cdot \phi_{\text {sol }} \\
& \left.C_{e n v}{ }^{*} \cdot \frac{d T_{e n v}}{d t}=U_{[e n v-e x t]}{ }^{*} \cdot\left(T_{e x t}-T_{e n v}\right)+U_{[a i r-e n v}\right]^{*} \cdot\left(T_{\text {air }}-T_{e n v}\right)+k_{e n v}^{s}{ }^{*} \cdot \phi_{\text {sol }} \\
& C_{\text {mass }}{ }^{*} \cdot \frac{d T_{\text {mass }}}{d t}=U_{[\text {air-mass }}{ }^{*} \cdot\left(T_{\text {air }}-T_{\text {mass }}\right)+k_{\text {mass }}^{s}{ }^{*} \cdot \phi_{\text {sol }} \\
& C_{e m}{ }^{*} \cdot \frac{d T_{e m}}{d t}=U_{[a i r-e m]}{ }^{*} \cdot\left(T_{a i r}-T_{e m}\right)+\dot{m} \cdot c_{p} \cdot\left(T_{c i r}-T_{e m}\right) \\
& C_{c i r}^{*} \cdot \frac{d T_{c i r}}{d t}=\eta_{l}^{*} \cdot \Phi_{S S T}+\dot{m} \cdot c_{p} \cdot\left(T_{e m}-T_{c i r}\right) \\
& \Phi_{S S T}=\Phi_{S S T}^{\max } \cdot \llbracket G_{c i r}^{p *} \cdot\left(T_{\text {cir }}^{\text {set }}-T_{\text {cir }}\right) \rrbracket_{0}^{1} \\
& \dot{m}=\dot{m}^{\text {max }} \cdot \llbracket G_{\text {air }}^{p^{*}} \cdot\left(T_{\text {air }}^{\text {set }}-T_{\text {air }}\right) \rrbracket_{0}^{1} \\
& \text { With the notation } y=\llbracket x \rrbracket_{a}^{b} \Rightarrow\left\{\begin{array}{c}
y=x \text { if } a \leq x \leq b \\
y=a \text { if } x<a \\
y=b \text { if } x>b
\end{array}\right.
\end{aligned}
$$

As can be derived from the equations, the model has 5 lumped nodes each having a homogeneous mean temperature and an associated thermal capacitance. They represent:

- Indoor air of temperature $T_{\text {air }}$ and thermal capacitance $C_{\text {air }}{ }^{*}$.

- Envelope of temperature $T_{e n v}$ and thermal capacitance $C_{e n v}{ }^{*}$.

- Internal mass of temperature $T_{\text {mass }}$ and thermal capacitance $C_{\text {mass }}{ }^{*}$. 
- Heat emitters of temperature $T_{e m}$ and thermal capacitance $C_{e m}{ }^{*}$.

- Heating circuit of temperature $T_{\text {cir }}$ and thermal capacitance $C_{\text {cir }}{ }^{*}$.

A power balance is established for each of these 5 nodes (Eqs. Eq. (1) to Eq. (5)).

The following heat exchange phenomena are modelled through heat transmittance coefficients:

- The air node exchanges heat directly with the external environment of temperature $T_{\text {ext }}$ due to ventilation through the heat transmittance coefficient $U_{[\text {air }- \text { ext }}{ }^{*}$.

- The air node and the envelope node exchange heat through $U_{[\text {air-env] }}{ }^{*}$.

- The air node and the internal mass node exchange heat through $U_{[\text {air-mass }]}{ }^{*}$.

- The air node and the heat emitters exchange heat through $U_{[\text {air-em] }}{ }^{*}$.

- The envelope node exchanges heat with the external environment through $U_{[e n v-e x t]}{ }^{*}$.

Solar heat gain is linearly modelled as the product of the global horizontal solar irradiation flux $\phi_{\text {sol }}$ by a fixed solar aperture surface area. It is injected into the first 3 nodes:

- The air node receives solar heat gain though the solar aperture $k_{\text {air }}^{s}{ }^{*}$.

- The envelope node receives solar heat gain though the solar aperture $k_{e n v}^{s}{ }^{*}$.

- The internal mass node receives solar heat gain though the solar aperture $k_{\text {mass }}^{s}{ }^{*}$.

The linear $3^{\text {rd }}$ order building model is represented under the thermal-electrical analogy in the RC network of Figure 4.

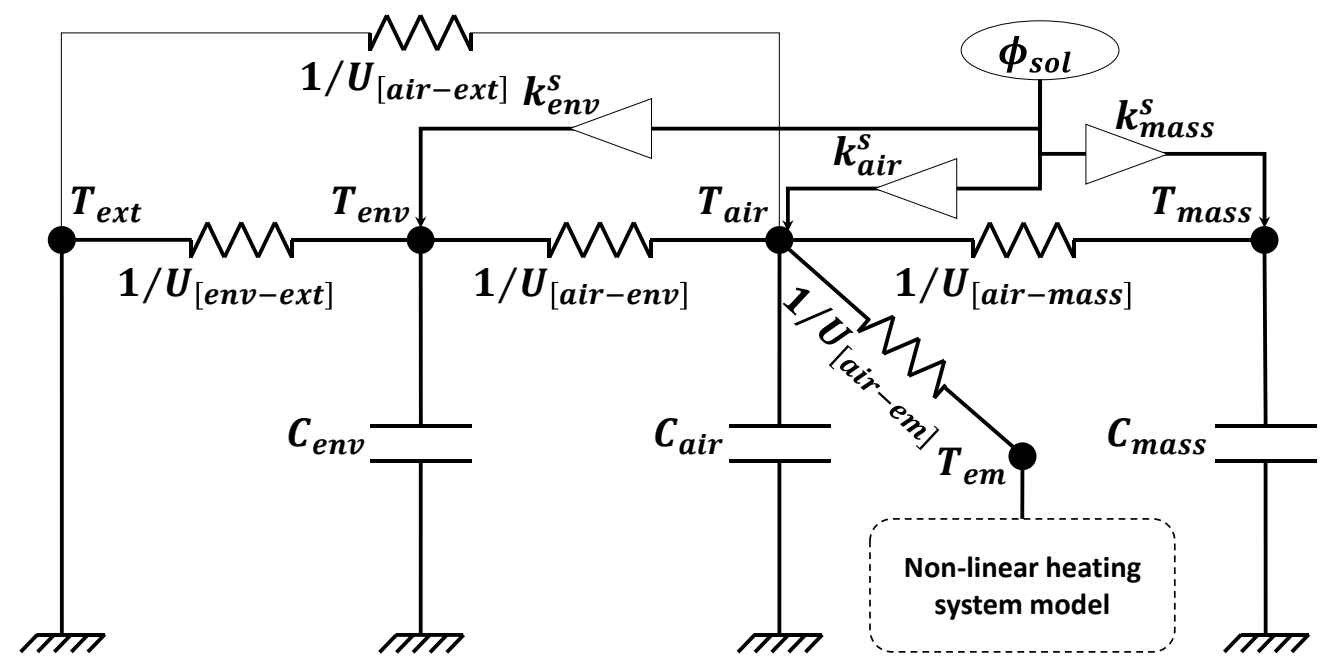

Figure 4. RC representation of the building model structure

The first non-linearity appears in the heating system model (Eqs. Eq. (4) and Eq. (5)) as the bilinear term between the heating water mass flowrate $\dot{m}$ and the temperature difference $\left(T_{c i r}-T_{e m}\right), c_{p}$ being the specific heat capacity of water. This term represents the heat flow from the heating circuit into the emitters. To take into account transmission losses in the heating circuit, we introduced an efficiency coefficient denoted $\eta_{l}{ }^{*}$ in Eq. Eq. (5).

The system model operates in a closed loop by regulating the heating circuit temperature and internal air temperature. In fact, $T_{\text {cir }}$ is regulated to a set point temperature $T_{\text {cir }}^{\text {set }}$ controlled at the substation level by the DHS operator. The substation heating power $\Phi_{S S T}$ may then be derived by Eq. Eq. (6) using a proportional gain $G_{c i r}^{p}{ }^{*}$ and bounded by the maximum sizing power of the substation $\Phi_{S S T}^{\max }$. This double-ended saturation expression is a second non-linearity in the heating system model. 
Whereas, $T_{\text {air }}$ is regulated to a set point temperature $T_{\text {air }}^{\text {set }}$ controlled by the building residents acting on their thermostatic radiator valves. Similarly to Eq. Eq. (6), Eq. Eq. (7) is a bounded formulation of the heating water mass flow rate $\dot{m}$ which is assumed to vary linearly to $T_{\text {air }}$ using a proportional gain $G_{\text {air }}^{p}{ }^{*}$. When the temperature difference reaches a given threshold, all thermostatic valves are fully open and $\dot{m}$ is saturated to its nominal value $\dot{m}^{\max }$. Note that $\Phi_{S S T}^{\max }$ and $\dot{m}^{\max }$ are parameters known beforehand and need not be identified. Indeed, $\Phi_{S S T}$ and $\dot{m}$ are the ROM outputs, both being non-intrusively measurable at the substation. When unsaturated, Eq. Eq. (7) may be used to observe $T_{\text {air }}$ and therefore this key equation dispenses with using intrusive indoor temperature in the parameter identification stage.

Overall, the model has:

- 1 controllable input $\left(T_{\text {cir }}^{\text {set }}\right)$.

- 3 uncontrollable inputs or disturbances $\left(T_{\text {ext }}, \phi_{\text {sol }}\right.$ and $\left.T_{\text {air }}^{\text {set }}\right)$.

- 2 outputs $\left(\Phi_{S S T}\right.$ and $\left.\dot{m}\right)$

- 5 variable states $\left(T_{\text {air }}, T_{\text {env }}, T_{\text {mass }} T_{e m}\right.$ and $\left.T_{\text {cir }}\right)$.

- 16 parameters to be identified.

\subsection{Parameters identification approach}

Given the ROM structure, parameters identification aims at finding an optimal set of parameters $\left(\theta^{o p t}\right)$ by minimizing the objective function (Eq. Eq. (8)). The goal is to minimize the error on the system output $\Phi_{S S T}$ weighted by $\frac{1}{3}$ and $\dot{m}$ weighted by $\frac{2}{3}$ between the ROM (superscript ...ROM ) and the building simulator (superscript ....sim), under the same input signals for a training period (TP) of 3 weeks. These two weighting factors are some tuning parameters in the identification process being chosen by means of a trial and error method to obtain satisfactory results.

$$
\theta^{\text {opt }}=\operatorname{argmin}\left(\int_{0}^{T P}\left[\frac{1}{3} \cdot\left(\frac{\Phi_{S S T}^{\text {Sim }}-\Phi_{S S T}^{R O M}}{\Phi_{S S T}^{\text {max }}}\right)^{2}+\frac{2}{3} \cdot\left(\frac{\dot{m}^{\text {sim }}-\dot{m}^{R O M}}{\dot{m}^{\text {max }}}\right)^{2}\right] d t\right)
$$

The novelty in this identification approach is being feasible at a DHS level since it only requires nonintrusive data available at the substation.

The deterministic search for $\theta^{\text {opt }}$ is carried out using GenOpt. GenOpt is an optimization software conceived to solve optimization problems with computationally expensive objective functions assessed by an external simulation tool such as Dymola. It is used in the identification problem to iteratively test new parameters, based on previous trails dictated by a search algorithm. GenOpt provides several optimization algorithms for multi-variables problems. A hybrid meta-heuristic algorithm is selected; it starts with a Particle Swarm Optimization on a coarse mesh of 150 generations of 150 particles each, and then refines the search results with a Hooke-Jeeves pattern search until the convergence criterion is met [33].

First, historical data under the conditions described in Section 3.3 is generated. Simulation input $\left\{T_{\text {ext }}, \phi_{\text {sol }}, T_{\text {air }}^{\text {set }}, T_{\text {cir }}^{\text {set }}\right\}$ and output $\left\{\Phi_{S S T}, \dot{m}\right\}$ signals are saved to a text file. The ROM is coded in a separate Dymola model which reads the inputs from the text file and returns the value of Eq. Eq. (8). During the identification process, the ROM's parameter set is iteratively updated by the GenOpt search algorithm according to the result of Eq. Eq. (8).

We make sure to initialize the search with reasonable parameters. The searched parameters are also normalized with respect to the initial values and the normalized search space is limited between $1 / 3$ and 3 for each parameter. 


\subsection{Data generation conditions}

The higher-order complex building simulator of the case-study building described in Section 2 is used as a data generator in replacement of measured historical data. The main conditions of data generation are:

- The radiators water temperature $\left(T_{c i r}^{\text {set }}\right)$ is not constant. Its setting point is linked to the exterior temperature with a heating curve so as to reproduce WC control adopted nowadays in most DHSs. Furthermore, the water set-point temperature is restrained to $35^{\circ} \mathrm{C}$ during night-time as a kind of power set-back. This is important to stimulate the thermal dynamics of the heating circuit, and therefore enhance the identifiability of the thermal capacitance associated to it in the ROM.

- The air set-point temperature $\left(T_{\text {air }}^{\text {set }}\right)$ in all zones of the building is constant and equal to $20^{\circ} \mathrm{C}$.

- The air renewal rate in all zones is also constant and equal to $0.3 \mathrm{Vol} / \mathrm{hr}$.

The assumptions of perfectly mastered internal set-point temperature and air renewal rate are indeed strong; in real-life, they are varying, unknown or uncertain. However, it is assumed that the stochastic internal gain signal added to the simulator aggregates all the uncertainties of the system.

Under these conditions, two sets of data are generated with a sampling period of 5 minutes for the outputs:

- From December $10^{\text {th }}$ to the $31^{\text {st }}$ for the training.

- From January $4^{\text {th }}$ to the $25^{\text {th }}$ for the validation.

\subsection{Performance criteria}

To assess the quality of the identified model, three criteria are evaluated:

- Relative errors on the ROM outputs (over the training and the validation periods):

- Relative error on $\Phi_{S S T}$ :

$$
\varepsilon_{\Phi_{S S T}}=\frac{\Phi_{S S T}^{R O M}-\Phi_{S S T}^{S i m}}{\Phi_{S S T}^{\max }-\overline{\Phi_{S S T}^{S l m}}} \times 100
$$

○ Relative error on $\dot{m}$ :

$$
\varepsilon_{\dot{m}}=\frac{\dot{m}^{R O M}-\dot{m}^{\text {sim }}}{\dot{m}^{\text {max }}-\dot{m}^{\text {slm }}} \times 100
$$

- Error on $T_{\text {air }}$ (over the training and the validation periods). $\overline{T_{a l r}^{s l m}}$ is the arithmetic mean of the simulator's zone temperatures weighted by their respective floor surface areas:

$$
\varepsilon_{T_{a i r}}=T_{\text {air }}^{R O M}-\overline{T_{\text {alr }}^{\text {Slm }}}
$$

- Physical relevance of the building equivalent heat loss coefficient $U_{e q}$ calculated according to Eq. Eq. (12) with the identified parameters by comparing its value to $\widehat{U}_{e q}$ estimated under Le Salammbô steady-state sizing conditions with $\Phi_{S S T}^{\max }=8600 \mathrm{~W}, T_{\text {air }}^{\text {sizing }}=20^{\circ} \mathrm{C}$ and $T_{\text {ext }}^{\text {sizing }}=-11^{\circ} \mathrm{C}$ :

$$
\begin{gathered}
U_{e q}=\frac{U_{i} \cdot U_{o}+U_{o} \cdot U_{v}+U_{v} \cdot U_{i}}{U_{i}+U_{o}} \\
\widehat{U}_{e q}=\frac{\Phi_{S S T}^{\max }}{T_{\text {air }}^{\text {sizing }}-T_{\text {ext }}^{\text {sizing }}}
\end{gathered}
$$




\subsection{Numerical results}

The developed ROM identification approach is demonstrated on the case-study building of Section 2.2. With a reasonable initial guess based on roughly approximated physical considerations, GenOpt converges to the identified parameters, listed in Table 1, after about $25 \mathrm{~K}$ simulations during around 30 minutes using an 18-core, 36-thread processor machine.

\begin{tabular}{|c|c|c|c|}
\hline Parameter & Identified value & Parameter & Identified Value \\
\hline $\boldsymbol{C}_{\text {air }}{ }^{*}$ & $2.58 \times 10^{7}(\mathrm{~J} / \mathrm{K})$ & $\boldsymbol{U}_{[\text {air-ext }]}{ }^{*}$ & $225(W / K)$ \\
\hline$C_{e n v}{ }^{*}$ & $1.78 \times 10^{8}(\mathrm{~J} / \mathrm{K})$ & $U_{[a i r-e n v]}{ }^{*}$ & $24.24(W / K)$ \\
\hline$C_{\text {mass }}{ }^{*}$ & $1.68 \times 10^{8}(\mathrm{~J} / \mathrm{K})$ & $\boldsymbol{U}_{[\text {air-mass }]}{ }^{*}$ & $3060(W / K)$ \\
\hline $\boldsymbol{C}_{\boldsymbol{e m}}{ }^{*}$ & $6.90 \times 10^{3}(\mathrm{~J} / \mathrm{K})$ & $\boldsymbol{U}_{[\text {air-em }]}{ }^{*}$ & $380(W / K)$ \\
\hline$C_{c i r}{ }^{*}$ & $2.72 \times 10^{5}(\mathrm{~J} / \mathrm{K})$ & $U_{[e n v-e x t]}{ }^{*}$ & $1840(W / K)$ \\
\hline $\boldsymbol{k}_{\text {air }}^{\boldsymbol{s}}{ }^{*}$ & $13.05\left(\mathrm{~m}^{2}\right)$ & $\eta_{l}^{*}$ & $0.95(-)$ \\
\hline $\boldsymbol{k}_{\text {env }}^{s}{ }^{*}$ & $15.3\left(\mathrm{~m}^{2}\right)$ & $G_{c i r}^{p *}$ & $0.32(1 / K)$ \\
\hline $\boldsymbol{k}_{\text {mass }}^{s}{ }^{*}$ & $5.1\left(m^{2}\right)$ & $G_{\text {air }}^{p *}$ & $0.5(1 / K)$ \\
\hline
\end{tabular}

Table 1. Identified parameters for the case-study building

To analyse the performance criteria, the error distributions obtained from the identified ROM output are analysed. $\varepsilon_{\Phi_{S S T}}$ of Eq. Eq. (9) is represented in Figure 5 and $\varepsilon_{\dot{m}}$ of Eq. Eq. (10) is represented in Figure 6 . The best-fit Gaussian curves in the plots give the mean and the standard deviation of the errors. These values show that the mean error is very close to zero for both outputs and its degradation in the validation phase remains acceptable. However, it can be noted that the standard deviations almost double in the validation phase. 


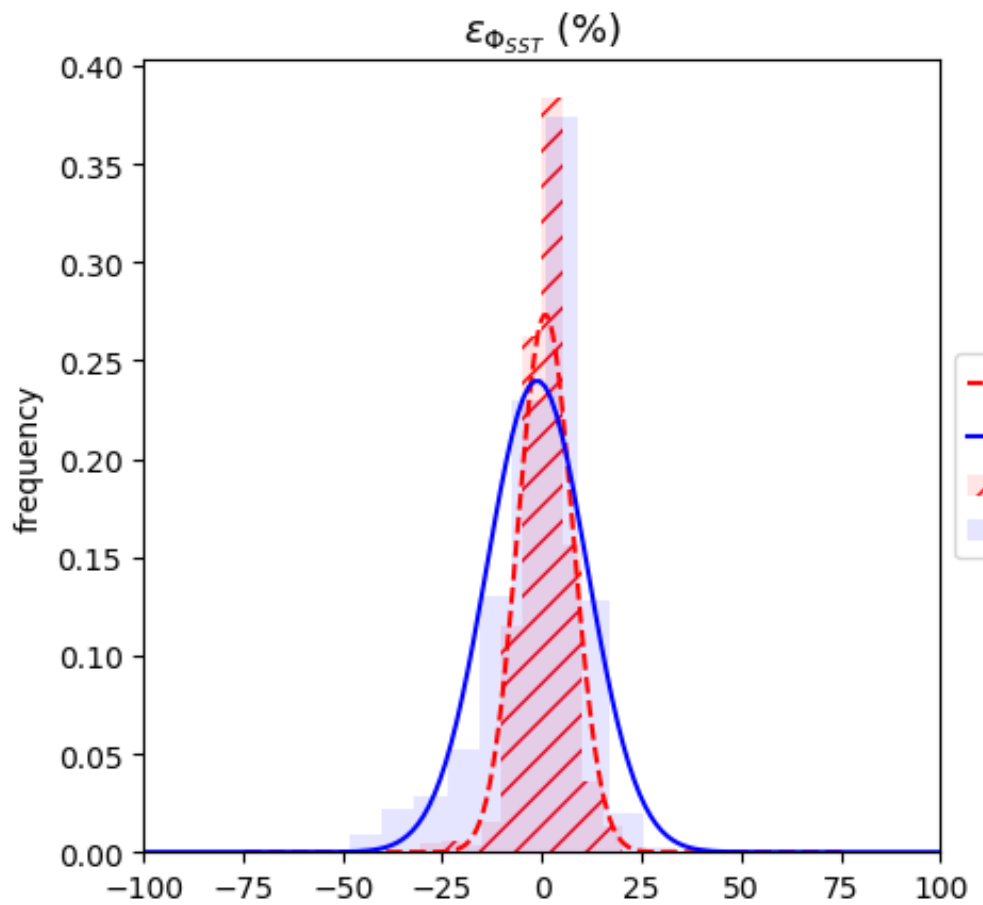

- -- Training $(\mu=0.88, \sigma=6.86)$

Validation $(\mu=-1.20, \sigma=12.58)$

Training

Validation

Figure 5. Histograms of $\varepsilon_{\Phi_{S S T}}$ (\%) for the training and validation phases, and their respective best-fit Gaussian curves

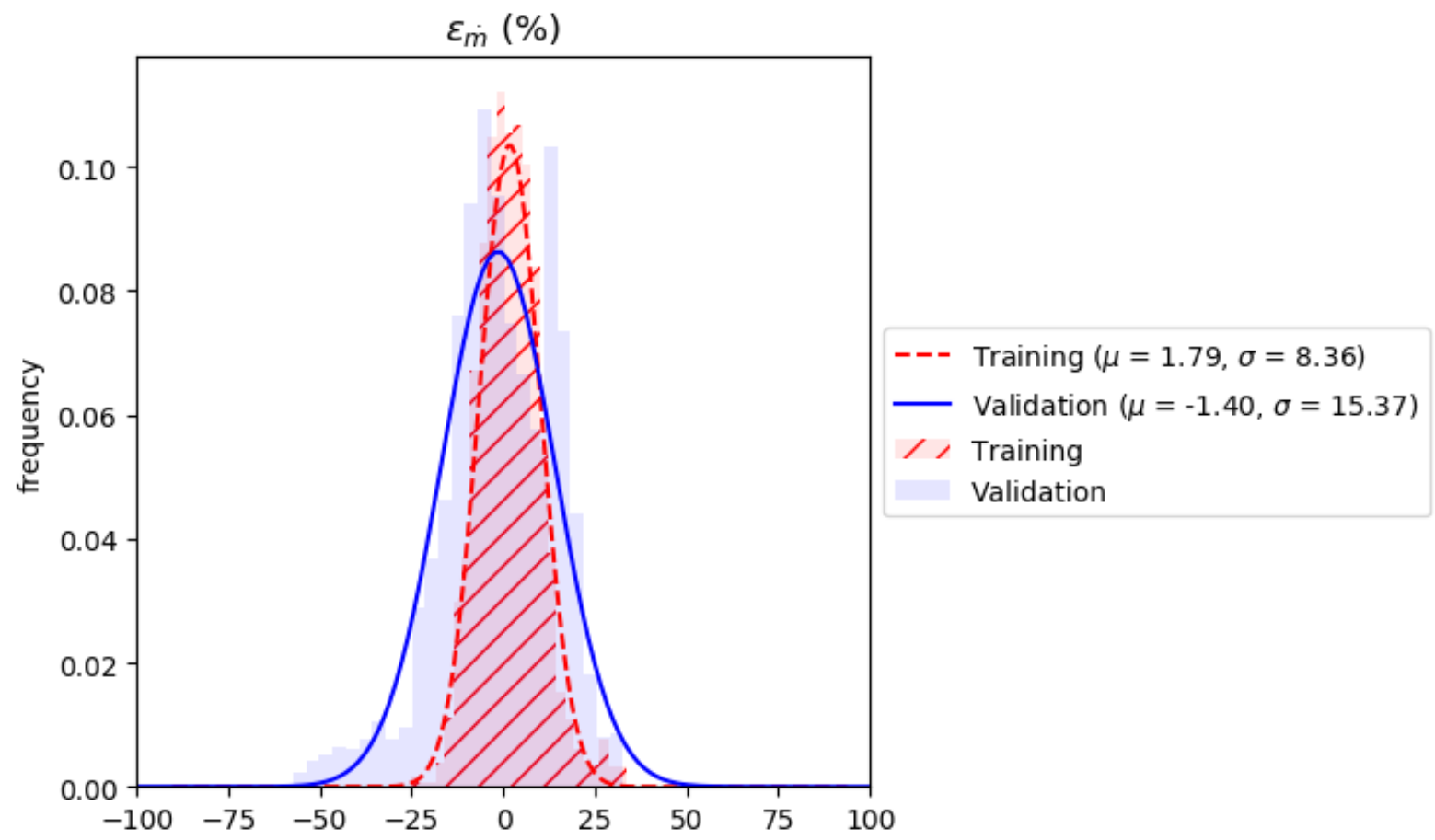

Figure 6. Histograms of $\varepsilon_{\dot{m}}(\%)$ for the training and validation phases, and their respective best-fit Gaussian curves

Next, the prediction error on the internal air temperature is examined. $\varepsilon_{T_{a i r}}$ of Eq. Eq. (11) is represented in Figure 7. Its mean error and standard deviation imply very good predictive ability during the identification and validation phases. Furthermore, the errors range between $-0.45^{\circ} \mathrm{C}$ and $0.27^{\circ} \mathrm{C}$ during identification, and between -0.36 and 0.59 during validation. These tight error ranges are quite satisfactory considering the fact that the identification approach did not rely on any internal temperature measures. This indicates that the ROM structure is physically wellrepresentative of the buildings thermal dynamics. 


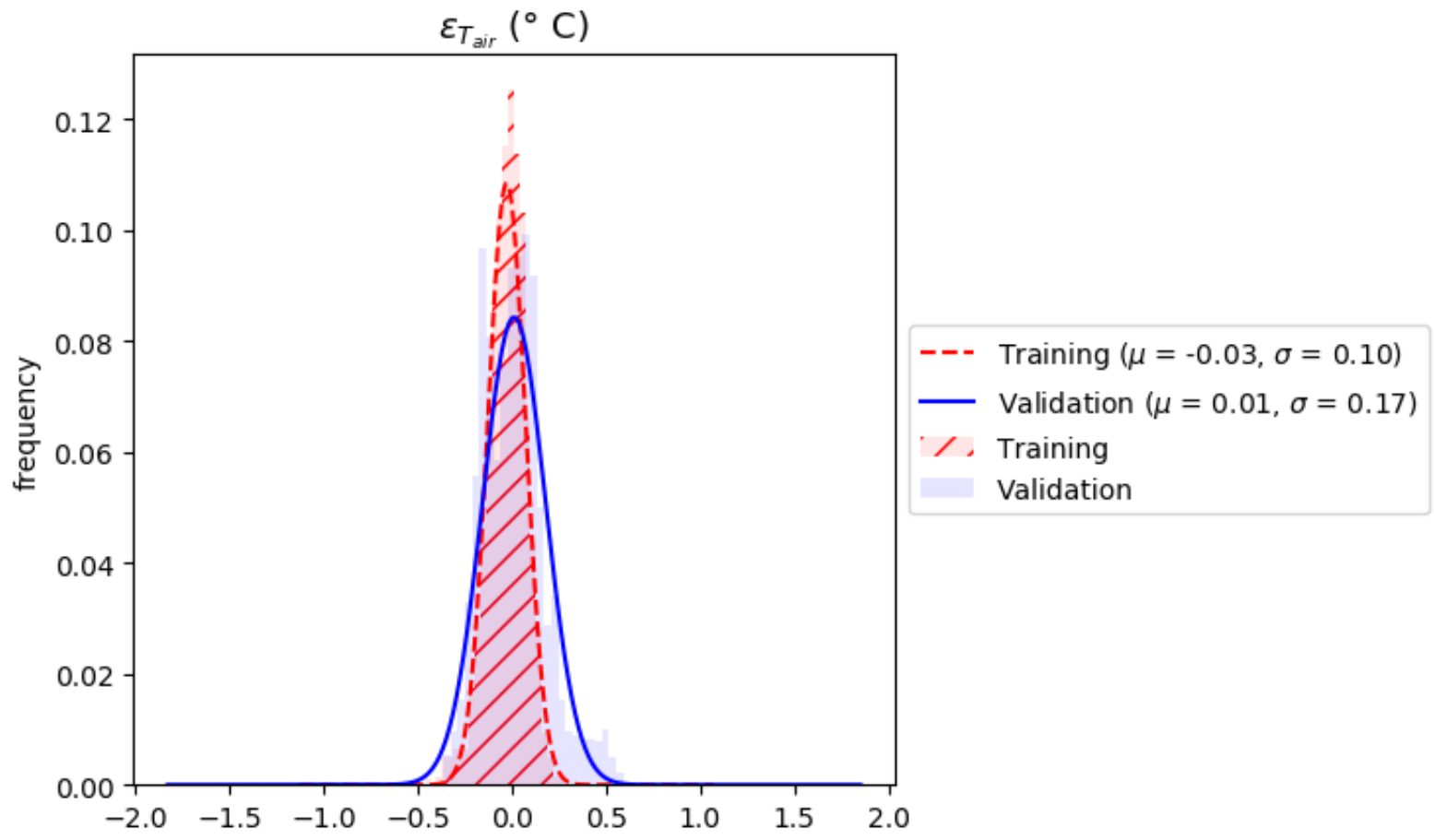

Figure 7. Histograms of $\varepsilon_{T_{a i r}}\left({ }^{\circ} \mathrm{C}\right)$ for the training and validation phases, and their respective best-fit Gaussian curves

A closer look at the internal temperature fit in Figure 8 shows that the largest discrepancies occur during night-time, when the internal gain magnitude is very low. Indeed, internal heat gain is not accounted for in the ROM equations (Eq. Eq. (1) to Eq. (7)). As a result, the identified parameters might be biased to compensate its influence. This eventually leads to greater errors in absence of internal gain.

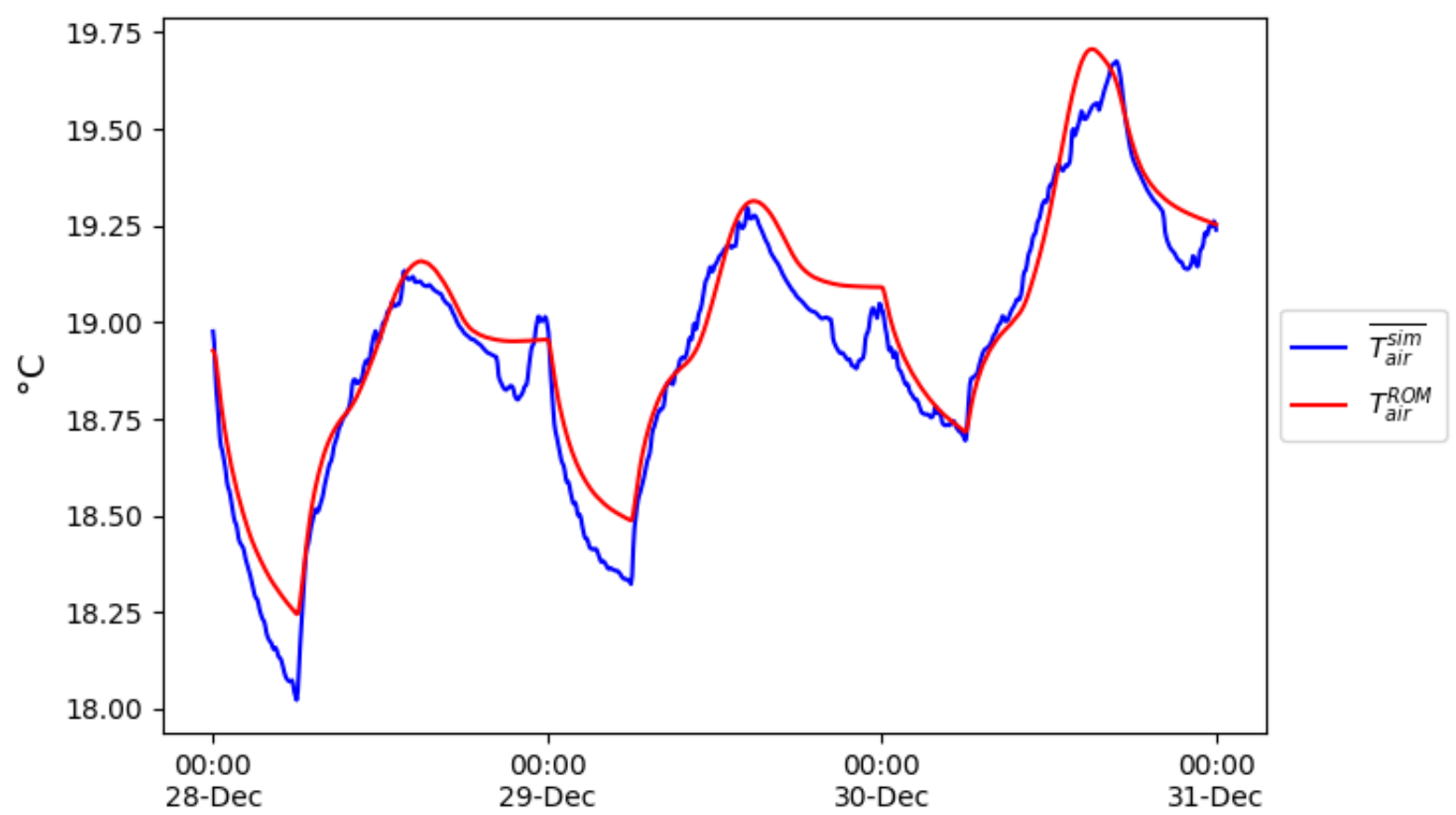

Figure 8. Internal air temperature fit 
For the final performance criterion, the building equivalent heat loss yields a difference of about 11 $\%$ between $U_{e q}=249 \mathrm{~W} / \mathrm{K}$ and $\widehat{U}_{e q}=277 \mathrm{~W} / \mathrm{K}$. Again, it can be interpreted that the parameters might be slightly biased, i.e. corresponding to over-estimated solar aperture surface areas and underestimated heat loss coefficients, to compensate the effect of internal heat gain.

The ROM structure and parameters identification approach was tested on 2 other case-study buildings from distinct energy classes to consolidate the hereby made conclusions. Results show that the overall approach yields more accurate results when applied to buildings that are less sensitive to internal heat gain, typically poorly insulated buildings where internal heat gain constitutes only a little fraction of the space-heating load [34].

As a conclusion, the performance criteria of the identified ROM are reasonably acceptable. Consequently, it may be used for an elementary test of MPC. 


\section{Flexible control of space-heating demand}

\subsection{Formulation}

MILP formalism is commonly used in the literature to solve electrical and thermal grids optimization problems $[35,36]$. Particularly for DHSs operational optimization exploiting short-term heat storage within the buildings mass, authors in [37] present a comprehensive global optimization problem using a technique to solve non-linear problems by multiple MILP. Buildings for energy storage are also studied in [38] under the MILP formalism applied to linear models and in [39] after piecewiselinear approximations of non-linear phenomena. Other formalisms, such as quadratic programming $[40,41]$ or heuristics [42] may also be adopted.

In this section, a MILP-based MPC scheme for flexible space-heating demand management is presented with an application to the case-study building of Section 2, based on its ROM identified in Section 3.

The receding horizon principle is implemented in a co-simulation platform called PEGASE [43]. At each time step $\Delta t=15$ minutes, the objective function (Section 4.1.1) subject to a set of linearized constraints (Section 4.1.2) is solved over a future horizon $H=24$ hours under perfect weather and energy cost predictions. The choice of the prediction horizon is conveniently made based on the building time constant which is estimated to 24 hours. Larger horizon imply longer computation times without greatly impacting the solution. The solution yields an optimal planning for the model controllable input over the anticipated receding horizon; only the first decision from the controller is applied to the building simulator, encapsulated in an Functional Mock-up Unit (FMU) [44], before shifting the time window and re-solving the problem over the updated horizon.

\subsubsection{Objective function}

Flexible space-heating demand management consists in modulating $T_{\text {air }}$ within a thermal comfort zone so as to economize heating costs. Whereas, conventional control aims at regulating $T_{\text {air }}$ to $T_{\text {air }}^{\text {set }}$ at all energy costs.

To model this flexibility aspect, we introduce a temperature denoted $T_{\text {air }}^{\text {target }}$ (Eq. Eq. (14)), lower than $T_{\text {air }}^{\text {set }}$ by $\varepsilon^{\text {comf }}$ ( $\varepsilon^{\text {comf }}>0$ defines the comfort zone).

$$
T_{\text {air }}^{\text {target }}=T_{\text {air }}^{\text {set }}-\varepsilon^{\text {comf }}
$$

Therefore, a discomfort can be penalized as $T_{\text {air }}$ deviates from $T_{\text {air }}^{\text {target }}$ (rather than $T_{\text {air }}^{\text {set }}$ ). This is expressed by introducing a new variable, $\Delta T_{\text {air }}^{\text {targt }}$ (Eq. Eq. (15)).

$$
\Delta T_{\text {air }}^{\text {target }}=T_{\text {air }}-T_{\text {air }}^{\text {target }}
$$

Depending on the sign of $\Delta T_{\text {air }}^{\text {target }}$, we calculate the over-heating and under-heating temperature deviations, respectively denoted $\Delta T_{\text {air }}^{\text {overheat }}$ and $\Delta T_{\text {air }}^{\text {underheat }}$ :

- $\Delta T_{\text {air }}^{\text {overheat }}$ equals 0 when $\Delta T_{\text {air }}^{\text {target }}<0\left(T_{\text {air }}<T_{\text {air }}^{\text {target }} \Rightarrow\right.$ no over-heat $)$ and takes a positive value when $\Delta T_{\text {air }}^{\text {target }}>0$ (Eq. Eq. (16)).

- $\Delta T_{\text {air }}^{\text {underheat }}$ equals 0 when $\Delta T_{\text {air }}^{\text {target }}>0\left(T_{\text {air }}>T_{\text {air }}^{\text {target }} \Rightarrow\right.$ no under-heat $)$ and takes a negative value when $\Delta T_{\text {air }}^{\text {target }}<0$ (Eq. Eq. (17)). 


$$
\Delta T_{\text {air }}^{\text {overheat }}=\llbracket \Delta T_{\text {air }}^{\text {target }} \rrbracket_{0}^{\infty}
$$

$$
\Delta T_{\text {air }}^{\text {underheat }}=\llbracket \Delta T_{\text {air }}^{\text {target }} \rrbracket_{-\infty}^{0}
$$

Then, the objective function (Eq. Eq. (18)) is formulated with 4 terms:

- $\quad c^{\text {energy }} \cdot \Phi_{S S T}$ is the space-heating energy cost

- $p^{\text {overheat }} \cdot \Delta T_{\text {air }}^{\text {overheat }}$ is the penalty for over-heating

- $p^{\text {underheat }} \cdot \Delta T_{\text {air }}^{\text {underheat }}$ is the penalty for under-heating

- $\quad p^{\text {stability }} \cdot T_{\text {cir }}$ is a penalty added to ensure that the control finds lower and more regular supply temperatures, therefore reduces heat losses and enhances the system stability.

Where $N_{\text {step }}$ is the number of steps in the prediction horizon (Eq. Eq. (19)), $c^{\text {energy }}$ is the energy cost in $€ / J$. $p^{\text {overheat }}, p^{\text {underheat }}$ and $p^{\text {stability }}$ are respectively the over-heat, under-heat and stability penalty costs in $€ /(K \cdot s)$.

$$
\min \sum_{i=1}^{N_{\text {step }}}\left(\begin{array}{c}
c^{\text {energy }}[i] \cdot \Phi_{S S T}[i] \cdot 60 \cdot \Delta t \\
+p^{\text {overheat }}[i] \cdot \Delta T_{\text {air }}^{\text {overheat }}[i] \cdot 60 \cdot \Delta t \\
+p^{\text {underheat }}[i] \cdot \Delta T_{\text {air }}^{\text {underheat }}[i] \cdot 60 \cdot \Delta t \\
+p^{\text {stability }}[i] \cdot T_{\text {cir }}[i] \cdot 60 \cdot \Delta t
\end{array}\right)
$$

Consequently, the optimizer should find a trade-off between the 3 terms that minimizes the objective function over the receding prediction horizon $H$. The dynamic dependency between $T_{\text {air }}$ and $\Phi_{S S T}$ is provided through the ROM equations which constitute the problem constraints. The more accurate the ROM, the more an absolute optimal solution for the given problem is approached.

For this study, it is assumed that perfectly predicted $c^{\text {energy }}$ are available. A correlation is made between over and under heat penalty costs and the mean energy cost over $H$. This is shown in Eqs. Eq. (20) and Eq. (21) with $\lambda^{\text {overheat }}=0.025(1 / K)$ and $\lambda^{\text {underheat }}=0.125(1 / K)$. Note that these values depend on consumer preferences between energy cost savings and deviation from the comfort zone. Multiplication by $\Phi_{S S T}^{\max }$ is necessary for a coherent unit conversion from $€ / J$ to $€ /(K \cdot S)$.

$$
\begin{gathered}
p^{\text {overheat }}[i]=\lambda^{\text {overheat }} \cdot \frac{1}{N_{\text {step }}} \cdot \sum_{i=1}^{N_{\text {step }}} c^{\text {energy }}[i] \cdot \Phi_{S S T}^{\max } \\
p^{\text {underheat }}[i]=-\lambda^{\text {underheat }} \cdot \frac{1}{N_{\text {step }}} \cdot \sum_{i=1}^{N_{\text {step }}} c^{\text {energy }}[i] \cdot \Phi_{S S T}^{\max }
\end{gathered}
$$

$p^{\text {stability }}[i]$ is set using Eq. Eq. (22) with $\lambda^{\text {stability }}=1 \mathrm{e}-5(1 / K)$.

$$
p^{\text {stability }}[i]=\lambda^{\text {stability }} \cdot c^{\text {energy }}[i] \cdot \Phi_{S S T}^{\max }
$$




\subsubsection{Constraints}

The MILP formalism is used to express the problem constraints which include the model equations (Eq. Eq. (1) to Eq. (7)) and the expressions of temperature deviation (Eqs. Eq. (16) and Eq. (17)).

First the ROM differential equations are discretized using the $1^{\text {st }}$ order Taylor polynomial at a time step equal to $\Delta t$. These equations are linear equality constraints. Then, equations that feature nonlinear expressions are linearized by introducing binary variables and inequality constraints. Concisely the non-linearilies are:

- Bilinear term $\dot{m} \cdot c_{p} \cdot\left(T_{c i r}-T_{e m}\right)$ in Eq. Eq. (4) and its opposite in Eq. Eq. (5) is handled by piecewise over and under-estimators by discretizing the space into $N_{d i s c}$ intervals, thus introducing $N_{\text {disc }}$ auxiliary binary variables at every time step.

- Saturation $\llbracket G_{c i r}^{p} \cdot\left(T_{c i r}^{s e t}-T_{c i r}\right) \rrbracket_{0}^{1}$ in Eq. Eq. (6) is handled by an exact piecewise linear formulation with 3 intervals introducing 3 auxiliary binary variables at every time step.

- Saturation $\llbracket G_{\text {air }}^{p^{*}} \cdot\left(T_{\text {air }}^{\text {set }}-T_{\text {air }}\right) \rrbracket_{0}^{1}$ in Eq. Eq. (7) is handled by an exact piecewise linear formulation with 3 intervals introducing 3 auxiliary binary variables at every time step.

- Saturation $\llbracket \Delta T_{\text {air }}^{\text {target }} \rrbracket_{0}^{\infty}$ in Eq. Eq. (16) and saturation $\llbracket \Delta T_{\text {air }}^{\text {target }} \rrbracket_{-\infty}^{0}$ in Eq. Eq. (17) is handled by an exact piecewise linear formulation with 2 intervals introducing 2 auxiliary binary variables at every time step.

Details of the formulation are given in the Appendix A. Linearization of the last 3 non-linear expressions is exact, i.e. it does not affect the precision of the ROM. However, the first linearization approximates the ROM to a linear form. The finer the discretization, the more accurate the approximation, the larger the computation times. Since we are dealing with an online optimization problem, a solution needs to be found within $\Delta t$, hence a trade-off between accuracy and computational speed needs to be made. A reasonable $N_{\text {disc }}=3$ is used in this application.

The problem is solved using open-source CPLEX as linear programming solver.

\subsection{Application}

A proof of concept of the MILP-based MPC is presented and compared with equivalent standard control in this section. The detailed building simulator is encapsulated in an FMU and used for this application. 5 scenarios are simulated from January $1^{\text {st }}$ to January $5^{\text {th }}$ with various control settings:

(1) A standard WC control using a static heating curve, $T_{\text {air }}^{\text {set }}=19.5^{\circ} \mathrm{C}$.

(2) A standard WC control using a static heating curve with a night-time set-back limiting $T_{\text {cir }}^{\text {set }}$ to $35^{\circ} \mathrm{C}$ from $11: 00 \mathrm{pm}$ to $6: 45 \mathrm{am}, T_{\text {air }}^{\text {set }}=19.5^{\circ} \mathrm{C}$.

(3) A MILP-based MPC considering fixed $c^{\text {energy }}$ and fixed $\varepsilon^{\text {comf }}=0.5^{\circ} \mathrm{C}, T_{\text {air }}^{\text {set }}=20^{\circ} \mathrm{C} \Rightarrow T_{\text {air }}^{\text {target }}=$ $19.5^{\circ} \mathrm{C}$.

(4) A MILP-based MPC considering fixed $c^{\text {energy }}$ with $\varepsilon^{\text {comf }}=0.5^{\circ} \mathrm{C}$ during the day and $\varepsilon^{\text {comf }}=2^{\circ} \mathrm{C}$ from 11:00 pm to $6: 45 \mathrm{am}, T_{\text {air }}^{\text {set }}=20^{\circ} \mathrm{C} \Rightarrow 18^{\circ} \mathrm{C}<T_{\text {air }}^{\text {target }}<19.5^{\circ} \mathrm{C}$.

(5) A MILP-based MPC considering variable $c^{\text {energy }}$ and fixed $\varepsilon^{\text {comf }}=0.5^{\circ} \mathrm{C}, T_{\text {air }}^{\text {set }}=20^{\circ} \mathrm{C} \Rightarrow T_{\text {air }}^{\text {target }}=$ $19.5^{\circ} \mathrm{C}$.

Building thermal response is investigated by comparing equivalent control strategies. For MPC scenarios, we also compare the building mean internal air temperature $\overline{T_{\text {alr }}^{s l m}}$ to that predicted by the ROM $T_{\text {air }}^{R O M}$ and its linearized version $T_{\text {air }}^{O p t}$ on which the MILP controller was based.

\subsubsection{Scenarios without night-time set-back}


Scenarios (1) and (3) do not consider setting-back space-heating during night-time. Scenario (1) regulates the indoor temperature to $19.5^{\circ} \mathrm{C}$ and scenario (3) assumes flexible indoor temperature with a fixed controller target temperature of $19.5^{\circ} \mathrm{C}$. Therefore, both scenarios should lead to a comparable indoor climate. The comparison is depicted in Figure 9.

The top subplot of Figure 9 concerns only MPC, since standard WC is not influenced by energy costs or thermal flexibility. Under constant $c^{\text {energy }}$ and $\varepsilon^{\operatorname{comf}}$, the only variable predictions in the MPC moving horizon $H$ are weather conditions ( $2^{\text {nd }}$ subplot). We observe the anticipation of solar heat gain by the MPC controller, which reduces the supply water temperature ( ${ }^{\text {rd }}$ subplot) so as to subsequently reduce space heating during the solar irradiation peak ( $4^{\text {th }}$ subplot). The bottom subplot shows 3 temperature signals from the MPC: the blue $T_{\text {air }}^{O p t}$ is the one predicted to minimize the objective function by the controller after linearizing the ROM, the orange $T_{\text {air }}^{\text {ROM }}$ is the exact temperature produced by the ROM under the controller input and $T_{\text {air }}^{\text {sim }}$ is the actual indoor temperature generated by the building simulator under the controller input as well. There is a slight difference between $T_{\text {air }}^{O p t}$ and $T_{\text {air }}^{\text {ROM }}$ with $N_{\text {disc }}=3$. The accuracy could be enhanced by refining the discretization level, this eventually leads to more stable input $T_{\text {cir }}^{\text {set }}$, at the expense of computation time which is limited to 15 minutes. It is noted that there is a gap between $T_{\text {air }}^{\text {Opt }}$ and $T_{\text {air }}^{\text {ROM }}$ on one hand and $\overline{T_{\text {alr }}^{s l m}}$ on the other during the solar irradiation peak. This recalls the conclusion made in Section 3.5 regarding over-estimated solar aperture surface areas in the ROM identification.

Standard control relies on a heating curve that calculates $T_{\text {cir }}^{\text {set }}-W C\left(3^{\text {rd }}\right.$ subplot $)$ as a linear function of $T_{\text {ext }}$ ( $2^{\text {nd }}$ subplot). Clearly, this results in smoother supply water temperature, that is always greater than $T_{\text {cir }}^{\text {set }}-M P C$ particularly during the solar irradiation peaks. In fact, standard control does not foresee solar peaks, which leads to periods of over-heating with respect to $T_{\text {air }}^{\text {set }}$. Neither does it account for the thermal inertia of the building system, consequently only as $T_{\text {ext }}, \Phi_{S S T}$ increases resulting in slight under-heating. 

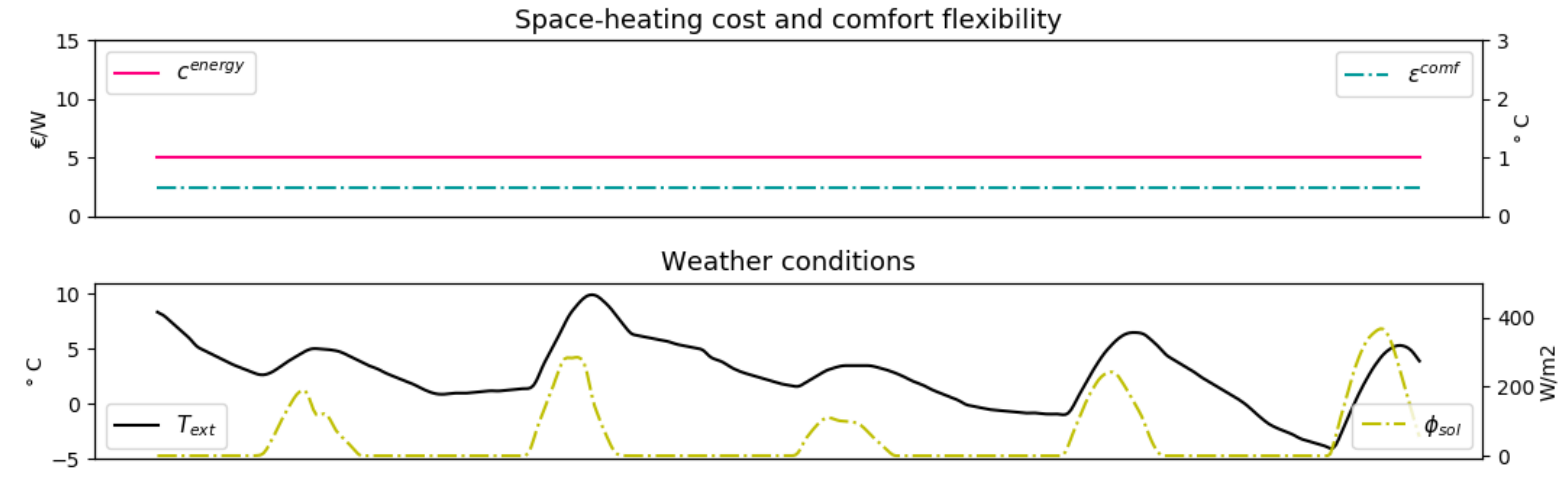

Supply water temperature

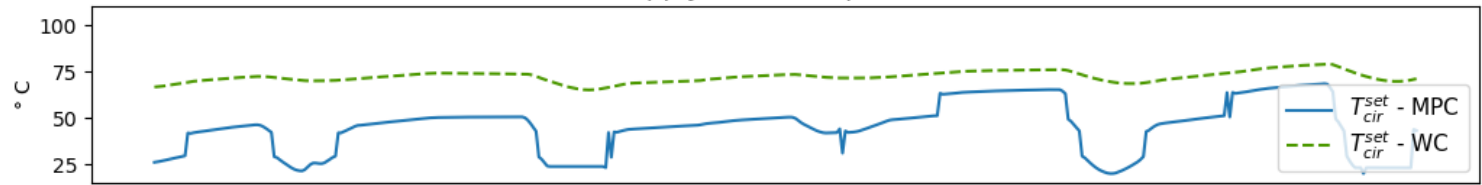

Space-heating power
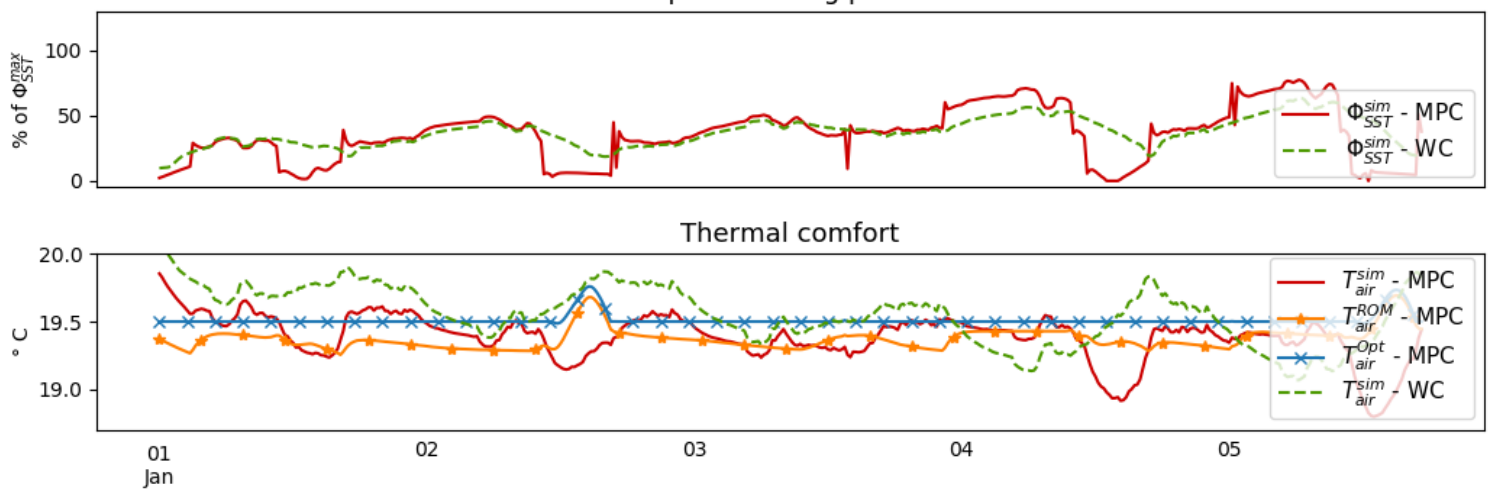

Figure 9. Comparison of scenarios (1) and (3)

\subsubsection{Scenarios with night-time set-back}

Scenarios (2) and (4) consider night-time set-back. Standard control systematically reduces the supply water temperature to $35^{\circ} \mathrm{C}$ during set-back periods, regardless of the indoor temperature drop, whereas MPC assumes this indoor temperature with a wider flexibility range and solves for the optimal supply temperature. Comparison of the perceived discomfort and the resulting spaceheating load is presented in Figure 10.

The top subplot of Figure 10 shows the flexibility profile for MPC which matches WC set-back periods. In both scenarios $T_{\text {cir }}^{\text {set }}$ is reduced during the same periods, however MPC launches and exits the set-back ahead of the pre-scheduled standard control because it accounts for the building thermal inertia ( $3^{\text {rd }}$ subplot). Yet, given constant energy costs, MPC does not allow peak-shaving in the early mornings ( $4^{\text {th }}$ subplot). In terms of comfort, MPC indoor temperature drops are sharper than those of WC since the minimum heating water temperature is below that of WC. Allowing a flexible $2^{\circ} \mathrm{C}$ drop, MPC exploits the full potential resulting in lower temperatures during the set-back (bottom subplot). 

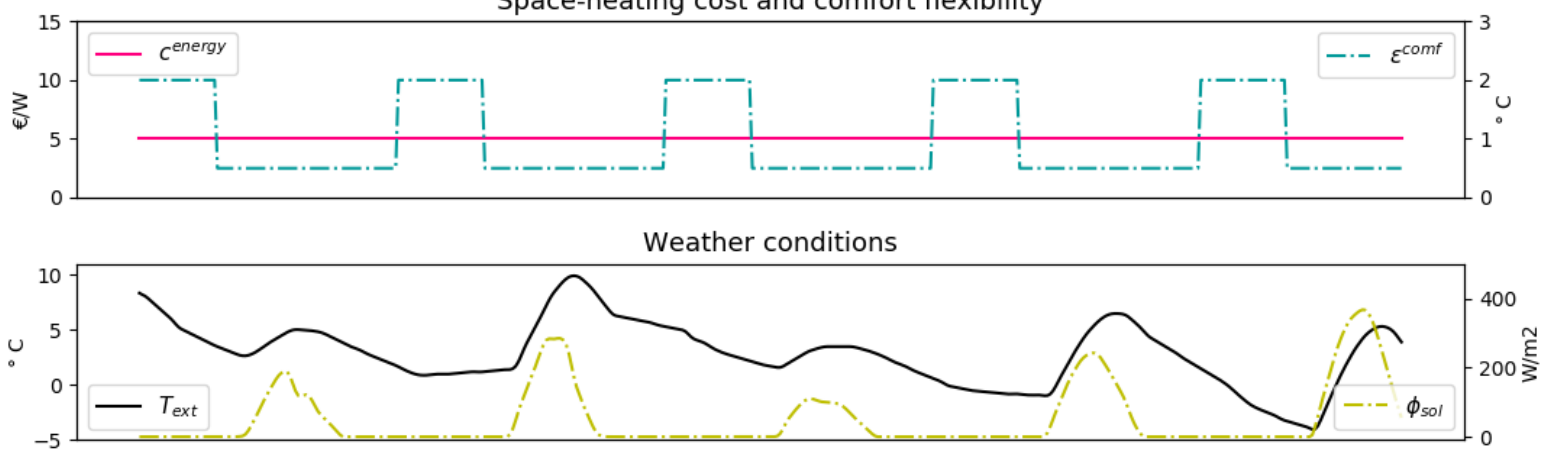

Supply water temperature

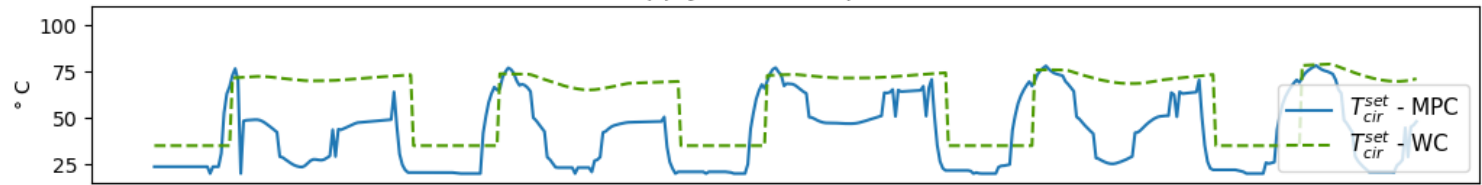

Space-heating power
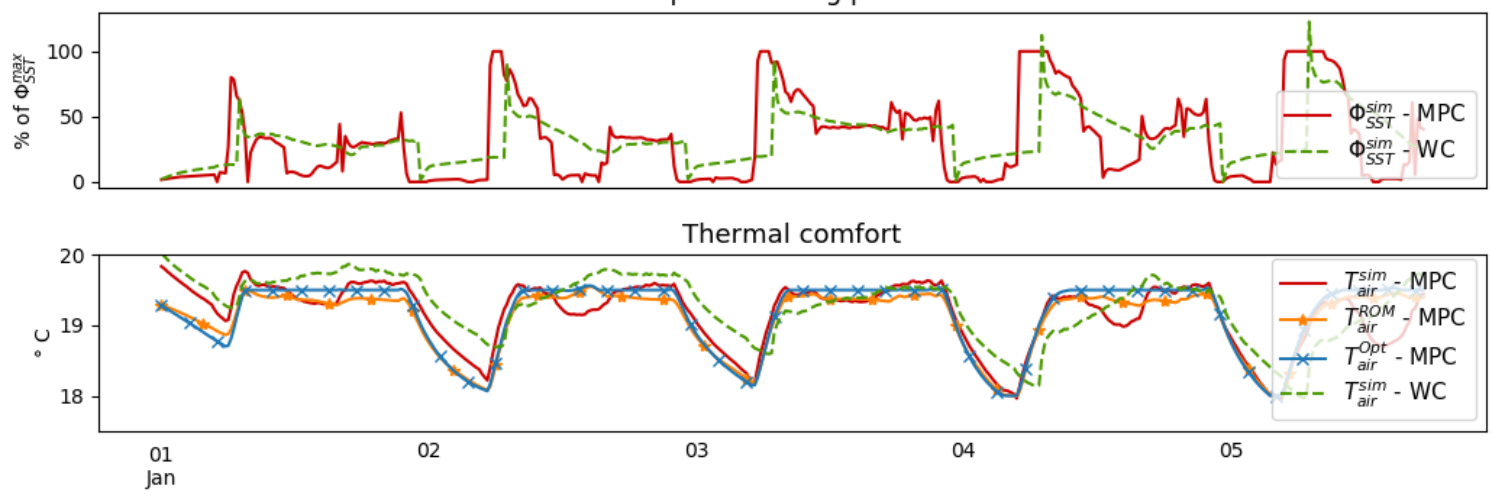

Figure 10. Comparison of scenarios (2) and (4)

\subsubsection{Scenario with energy price consideration}

MPC scenario (5) has no equivalent standard control considering predictions of energy costs.

The top subplot of Figure 11 shows the energy cost profile. The $3^{\text {rd }}, 4^{\text {th }}$ and bottom subplots depict how the flexible controller manages to reduce power consumption during high energy cost periods. The controller stores heat within the building system prior to the costs peak so as to discharge it during these periods and minimize thermal discomfort. Note the $T_{\text {air }}^{o p t}$ increase prior to the energy cost peak remains quite limited due to closing thermostatic radiator valves which are controlled by consumers settings $\left(T_{\text {air }}^{\text {set }}\right)$, not by the DHS operator. Indeed, the control actions take place at the substation level only. Otherwise, a more intensive short-term heat storage could be achieved. 

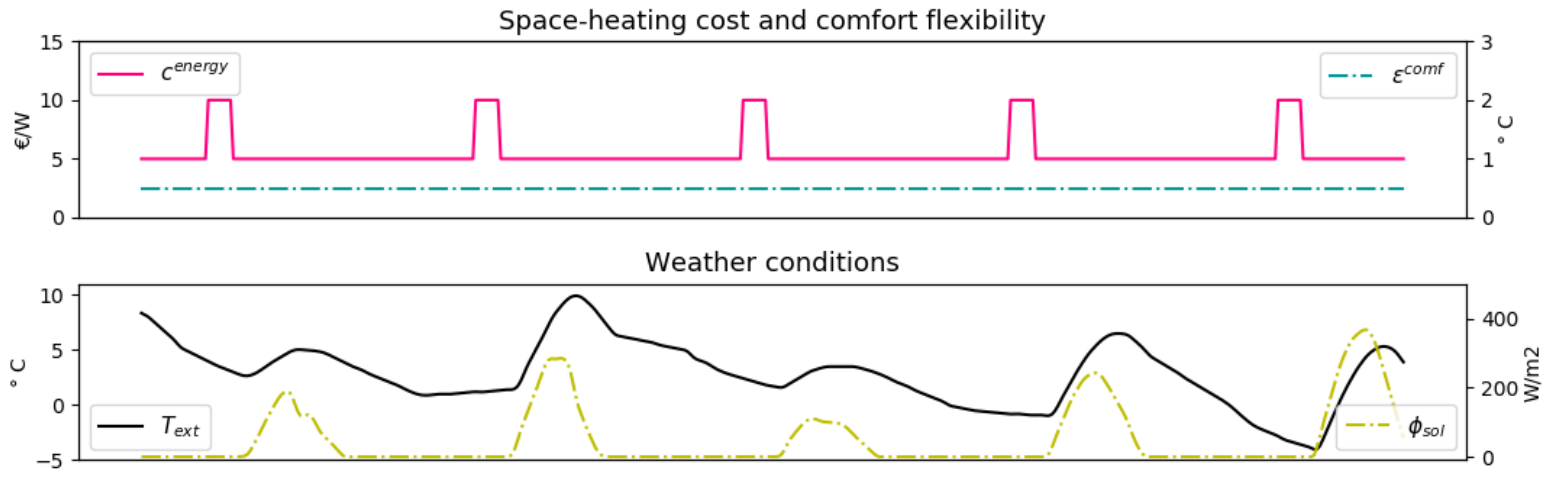

Supply water temperature

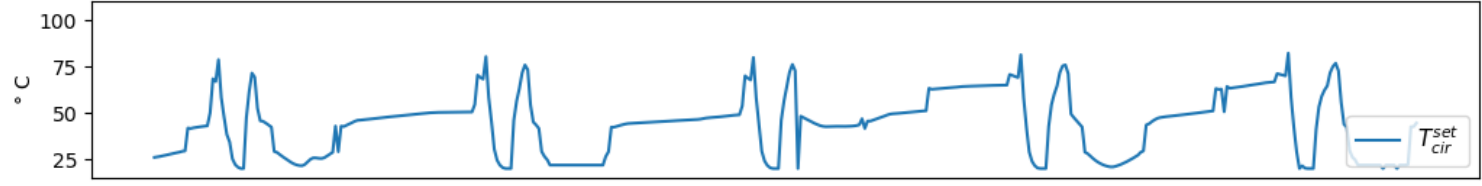

Space-heating power
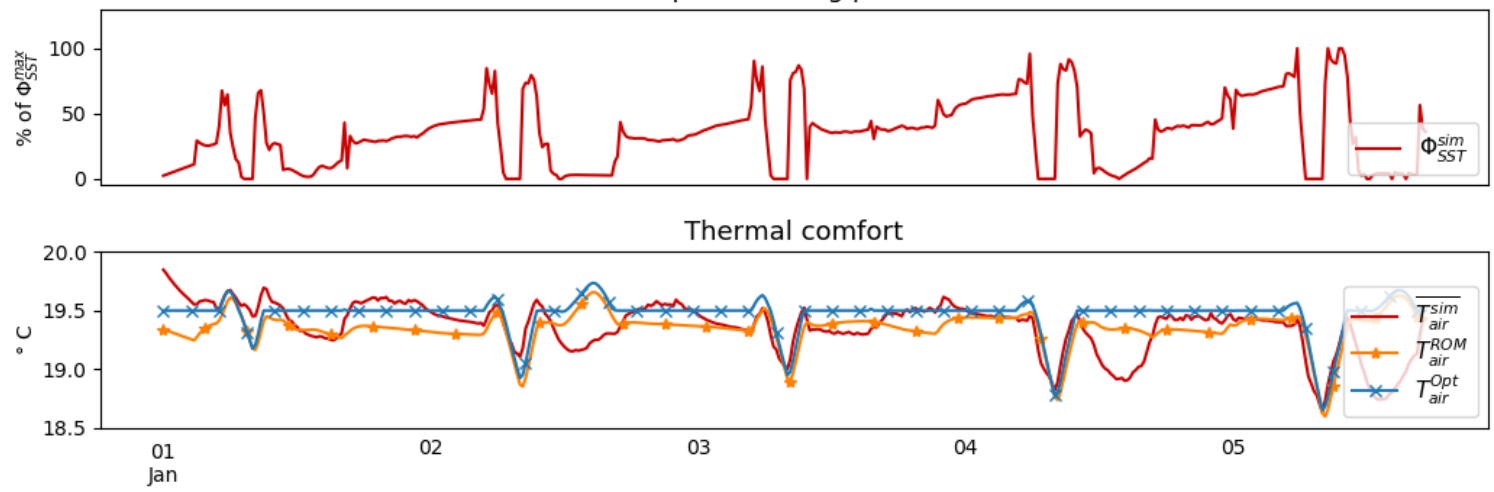

Figure 11. Space-heating MPC considering energy price variations and flexible comfort 


\section{Conclusion}

In this paper, a building model structure is presented. It features careful modelling of the internal mass thermal inertia and a non-linear heating system model. Parameters identification is carried out by minimizing the error on the model outputs including the substation space-heating power and mass flowrate, without using intrusive indoor measurements. The identified model was able to track the dynamics of the internal air temperature with acceptable accuracy. Using this model, a flexible MILP-based MPC is formulated after linearization. MPC performance is compared to equivalent conventional control scenarios. MPC with flexible comfort criteria and variable energy cost predictions seems promising in DHSs for it allows shifting and shaving space-heating consumption to off-peak periods, therefore reducing costs while maintaining decent thermal comfort conditions.

Several challenges are yet to be confronted. Discrepancies between the ROM and the building simulator inevitably exist. Uncertainly quantification and stochastic internal heat gain models might improve the ROM performance. In the control scheme, feedback might be necessary to keep the internal temperature from straying on the long run. Yet, we stick to the assumption that a feedback on the internal air temperature is not feasible at a DHS scale, instead we will use non-intrusive measurements to regularly update the model's states. This paper considered only a low-consumption case-study building. Other building archetypes will be investigated in more inclusive studies. Furthermore, uncertainties related to weather forecast and energy price variations are not treated in this work but should be integrated for a more consolidated strategy. Utterly, we look forward to a real-life application of the methodology on the demonstrator building of advanced control strategies, Le Salammbô.

\section{Acknowledgements}

We gratefully acknowledge ADEME (Agence de l'Environnement et de la Maîtrise de l'Énergie) for their financial contribution in funding the PhD thesis of Nadine Aoun and the City-zen project for their contributions. 


\section{Appendix A}

\section{MILP formulation}

Minimize:

$$
\begin{aligned}
\sum_{i=1}^{N_{\text {step }}}\left(c^{\text {energy }}[i]\right. & \cdot \Phi_{S S T}[i]+p^{\text {overheat }}[i] \cdot \Delta T_{\text {air }}^{\text {overheat }}[i]+p^{\text {underheat }}[i] \cdot \Delta T_{\text {air }}^{\text {underheat }}[i] \\
& \left.+p^{\text {stability }}[i] \cdot T_{\text {cir }}[i] \cdot 60 \cdot \Delta t\right)
\end{aligned}
$$

Subject to:

$\forall i \in\left[1, N_{\text {step }}\right]:$

Discretization of linear differential equations:

$C_{\text {air }} \cdot \frac{T_{\text {air }}[i]-T_{\text {air }}[i-1]}{\Delta t}=U_{[\text {air }-e x t]} \cdot\left(T_{\text {ext }}[i]-T_{\text {air }}[i]\right)+U_{[a i r-e n v]} \cdot\left(T_{\text {env }}[i]-\right.$

$\left.T_{\text {air }}[i]\right)+U_{[\text {air-mass }]} \cdot\left(T_{\text {mass }}[i]-T_{\text {air }}[i]\right)+U_{[\text {air-em }]} \cdot\left(T_{\text {em }}[i]-T_{\text {air }}[i]\right)+k_{\text {air }}^{s}$.

$\phi_{\text {sol }}[i]$

$C_{e n v} \cdot \frac{T_{e n v}[i]-T_{e n v}[i-1]}{\Delta t}=U_{[e n v-e x t]} \cdot\left(T_{e x t}[i]-T_{e n v}[i]\right)+U_{[a i r-e n v]} \cdot\left(T_{a i r}[i]-\right.$

$\left.T_{e n v}[i]\right)+k_{e n v}^{s} \cdot \phi_{\text {sol }}[i]$

$C_{\text {mass }} \cdot \frac{T_{\text {mass }}[i]-T_{\text {mass }}[i-1]}{\Delta t}=U_{[\text {air }- \text { mass }]} \cdot\left(T_{\text {air }}[i]-T_{\text {mass }}[i]\right)+k_{\text {mass }}^{s} \cdot \phi_{\text {sol }}[i]$

$C_{e m} \cdot \frac{T_{e m}[i]-T_{e m}[i-1]}{\Delta t}=U_{[a i r-e m]} \cdot\left(T_{a i r}[i]-T_{e m}[i]\right)+\Phi_{N L}[i]$

$C_{c i r} \cdot \frac{T_{c i r}[i]-T_{c i r}[i-1]}{\Delta t}=\eta_{l} \cdot \Phi_{S S T}[i]-\Phi_{N L}[i]$

Linearization of bilinear term $\Phi_{N L}=\dot{m} \cdot c_{p} \cdot\left(T_{\text {cir }}-T_{\text {em }}\right)$ using McCormick envelope [45] (Figure 12):

The approach consists of discretizing $\left(T_{\text {cir }}-T_{\text {em }}\right)$ into a vector of $\left(N_{\text {disc }}+1\right)$ uniformly spaced positive values $\Delta T_{N L}^{\text {disc }} ; \Delta T_{N L}^{\text {disc }}[j]$ is the discretized value of $\Delta T_{N L}$ at the beginning of interval $j$. This creates $N_{\text {disc }}$ equal intervals. Then, we introduce $N_{\text {disc }}$ auxiliary binary variables $\alpha_{N L}$ and auxiliary continuous variables $\Delta T_{N L}, \delta_{N L}$ and $\omega_{N L}$.

$\Delta T_{N L}[i]=T_{c i r}[i]-T_{e m}[i]$

$\sum_{j=1}^{N_{\text {disc }}} \alpha_{N L}[i][j]=1$

$\Delta T_{N L}[i]=\sum_{j=1}^{N_{\text {disc }}} \delta_{N L}[i][j]$

$\dot{m}[i]=\sum_{j=1}^{N_{\text {disc }}} \omega_{N L}[i][j]$

Eq. (A.10) 
$\forall j \in\left[1, N_{\text {disc }}\right]$

$$
\begin{aligned}
& \delta_{N L}[i][j] \geq \Delta T_{N L}^{d i s c}[j] \cdot \alpha_{N L}[i][j] \\
& \delta_{N L}[i][j] \leq \Delta T_{N L}^{d i s c}[j+1] \cdot \alpha_{N L}[i][j] \\
& \omega_{N L}[i][j] \geq \dot{m}^{\min } \cdot \alpha_{N L}[i][j] \\
& \omega_{N L}[i][j] \leq \dot{m}^{\max } \cdot \alpha_{N L}[i][j]
\end{aligned}
$$

$\frac{\Phi_{N L}[i]}{c_{p}} \geq \sum_{j=1}^{N_{\text {disc }}}\left(\dot{m}^{\text {min }} \cdot \delta_{N L}[i][j]+\Delta T_{N L}^{\text {disc }}[j] \cdot \omega_{N L}[i][j]-\dot{m}^{\text {min }} \cdot \Delta T_{N L}^{\text {disc }}[j] \cdot\right.$ $\left.\alpha_{N L}[i][j]\right)$

$\frac{\Phi_{N L}[i]}{c_{p}} \geq \sum_{j=1}^{N_{d i s c}}\left(\dot{m}^{\max } \cdot \delta_{N L}[i][j]+\Delta T_{N L}^{d i s c}[j+1] \cdot \omega_{N L}[i][j]-\dot{m}^{\max } \cdot \Delta T_{N L}^{d i s c}[j+1] \cdot\right.$ $\left.\alpha_{N L}[i][j]\right)$

$\frac{\Phi_{N L}[i]}{c_{p}} \leq \sum_{j=1}^{N_{\text {disc }}}\left(\dot{m}^{\mathrm{min}} \cdot \delta_{N L}[i][j]+\Delta T_{N L}^{\text {disc }}[j+1] \cdot \omega_{N L}[i][j]-\dot{m}^{\text {min }} \cdot \Delta T_{N L}^{d i s c}[j+1] \cdot\right.$ $\left.\alpha_{N L}[i][j]\right)$

$\frac{\Phi_{N L}[i]}{c_{p}} \leq \sum_{j=1}^{N_{d i s c}}\left(\dot{m}^{\max } \cdot \delta_{N L}[i][j]+\Delta T_{N L}^{d i s c}[j] \cdot \omega_{N L}[i][j]-\dot{m}^{\max } \cdot \Delta T_{N L}^{d i s c}[j] \cdot\right.$ $\left.\alpha_{N L}[i][j]\right)$

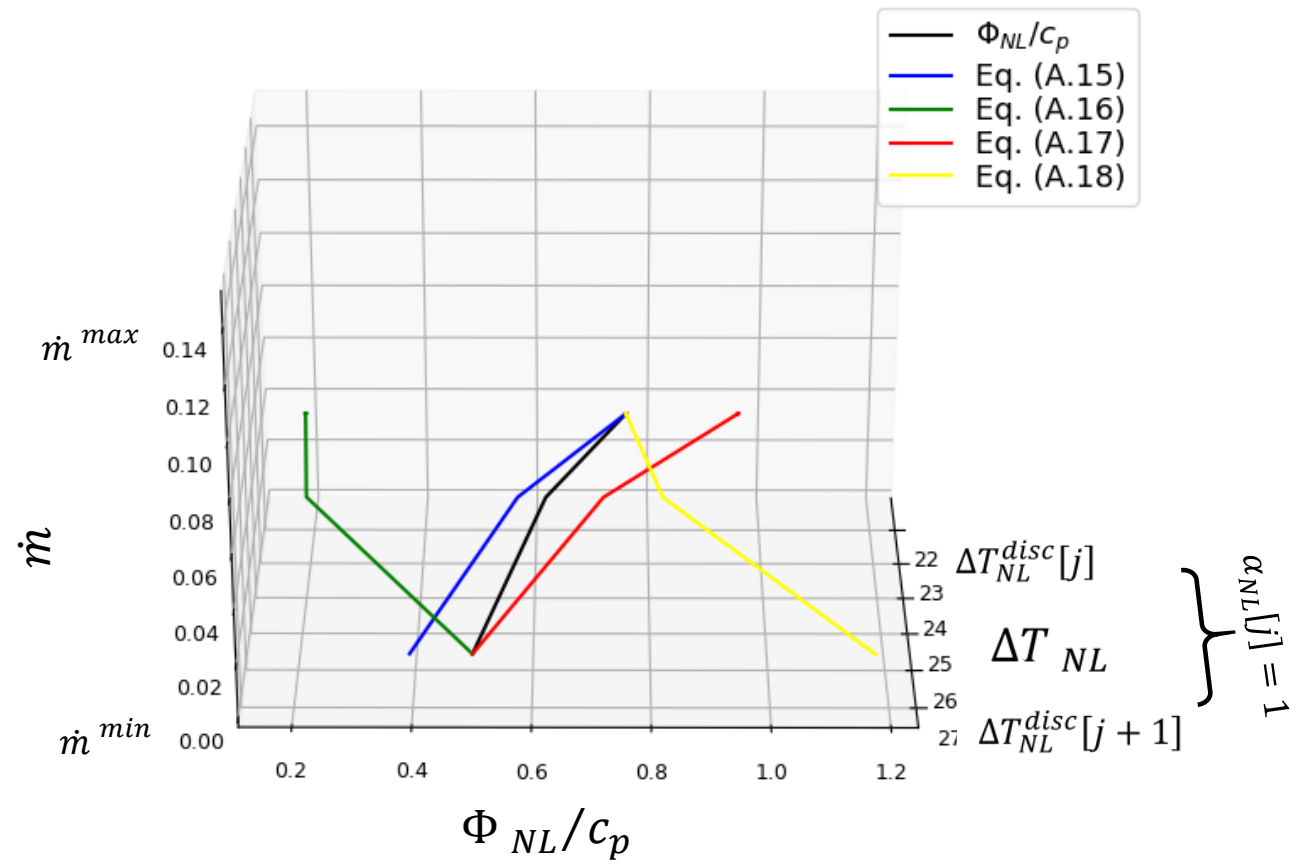

Figure 12. Representation of the bilinear term linearization using the McCormick envelope of under (blue and green lines) and over (red and yellow lines) estimators

Linearization of Eq. Eq. (6) by discretizing $T_{\text {cir }}^{\text {set }}-T_{\text {cir }}$ into 3 intervals and introducing 3 auxiliary binary variables $\alpha_{\Phi}$ and auxiliary continuous variables $\Delta T_{\text {cir }}, \rho_{\Phi}$ and $\beta_{\Phi}$ (Figure 13): 
$\Delta T_{\text {cir }}[i]=T_{\text {cir }}^{\text {set }}[i]-T_{\text {cir }}[i]$

Eq. (A.19)

$\rho_{\Phi}[i]=\frac{\Phi_{S S T}[i]}{\Phi_{S S T}^{\max }}$

Eq. (A.20)

$\sum_{j=1}^{3} \alpha_{\Phi}[i][j]=1$

Eq. (A.21)

$\forall j \in[1,3]$

$$
\beta_{\Phi}[i][j] \leq \alpha_{\Phi}[i][j]
$$

Eq. (A.22)

$\Delta T_{c i r}[i]=\Delta T_{c i r}^{\min } \cdot \alpha_{\Phi}[i][1]+\frac{1}{G_{p}^{c i r}} \cdot \alpha_{\Phi}[i][3]-\Delta T_{c i r}^{\min } \cdot \beta_{\Phi}[i][1]+\frac{1}{G_{p}^{c i r}} \cdot \beta_{\Phi}[i][2]+$ $\left(\Delta T_{\text {cir }}^{\min }-\frac{1}{G_{p}^{c i r}}\right) \cdot \beta_{\Phi}[i][3]$

$\rho_{\Phi}[i]=\alpha_{\Phi}[i][3]+\beta_{\Phi}[i][2]$

Eq. (A.24)

Linearization of Eq.Eq. (7) by discretizing $T_{\text {air }}^{\text {set }}-T_{\text {air }}$ into 3 intervals and introducing 3 auxiliary binary variables $\alpha_{\dot{m}}$ and auxiliary continuous variables $\Delta T_{\text {air }}, \rho_{\dot{m}}$ and $\beta_{\dot{m}}$ (Figure 13):

$\Delta T_{\text {air }}[i]=T_{\text {air }}^{\text {set }}[i]-T_{\text {air }}[i]$

$\rho_{\dot{m}}[i]=\frac{\dot{m}[i]}{\dot{m}^{\text {max }}}$

$\sum_{j=1}^{3} \alpha_{\dot{m}}[i][j]=1$

$\forall j \in[1,3]$

$$
\beta_{\dot{m}}[i][j] \leq \alpha_{\dot{m}}[i][j]
$$

$$
\begin{aligned}
& \Delta T_{\text {air }}[i]=\Delta T_{\text {air }}^{\text {min }} \cdot \alpha_{\dot{m}}[i][1]+\frac{1}{G_{p}^{\text {air }}} \cdot \alpha_{\dot{m}}[i][3]-\Delta T_{\text {air }}^{\text {min }} \cdot \beta_{\dot{m}}[i][1]+\frac{1}{G_{p}^{\text {air }}} \cdot \beta_{\dot{m}}[i][2]+ \\
& \left(\Delta T_{\text {air }}^{\text {min }}-\frac{1}{G_{p}^{\text {cir }}}\right) \cdot \beta_{\dot{m}}[i][3] \\
& \rho_{\dot{m}}[i]=\alpha_{\dot{m}}[i][3]+\beta_{\dot{m}}[i][2]
\end{aligned}
$$




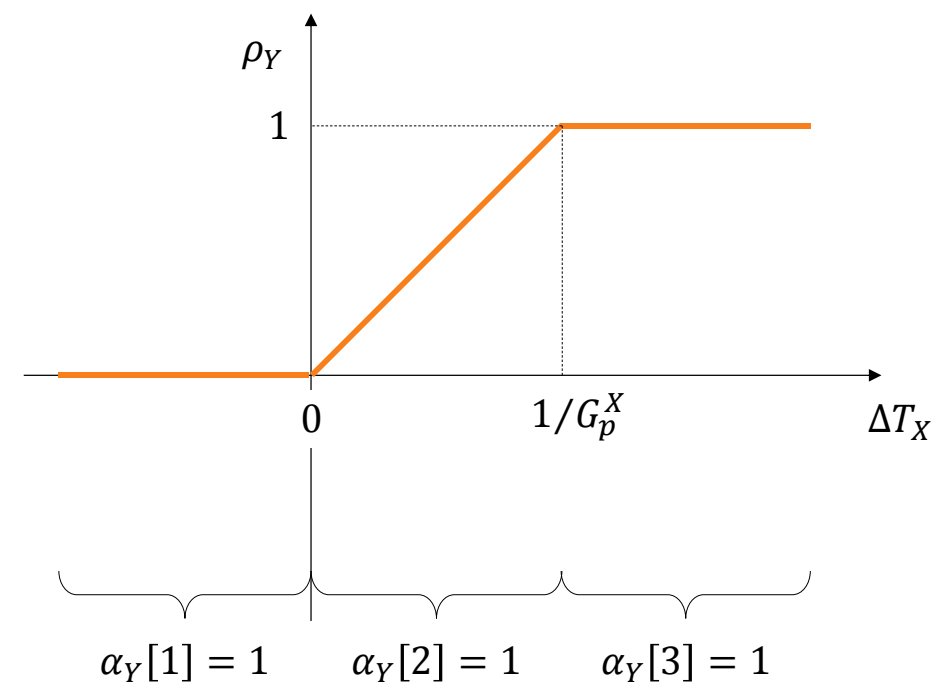

Figure 13. Representation of the saturation linearization:

$X=\operatorname{air}$ and $Y=\dot{m}$ for Eq. Eq. (6), $X=\operatorname{air}$ and $Y=\dot{m}$ for Eq. Eq. (7)

Linearization of Eq.Eq. (16) and Eq. (17) by discretizing $\Delta T_{\text {air }}^{\text {target }}$ into 2 intervals and introducing 2 auxiliary binary variables $\alpha_{m}$ and auxiliary continuous variables $T_{\text {air }}^{\text {target }}, \Delta T_{\text {air }}^{\text {target }}, \alpha_{\text {target }}$ and $\beta_{\text {target }}$ (Figure 14):

$T_{\text {air }}^{\text {target }}=T_{\text {air }}^{\text {set }}-\varepsilon^{\text {comf }}$

$\Delta T_{\text {air }}^{\text {target }}=T_{\text {air }}-T_{\text {air }}^{\text {target }}$

$\sum_{j=1}^{2} \alpha_{\text {target }}[i][j]=1$

$\forall j \in[1,2]$

$$
\beta_{\text {target }}[i][j] \leq \alpha_{\text {target }}[i][j]
$$

$\Delta T_{\text {air }}^{\text {target }}=\Delta T_{\text {target }}^{\min } \cdot \alpha_{\text {target }}[i][1]-\Delta T_{\text {target }}^{\min } \cdot \beta_{\text {target }}[i][1]+\Delta T_{\text {target }}^{\max } \cdot \beta_{\text {target }}[i][2]$

$\Delta T_{\text {air }}^{\text {overheat }}=\Delta T_{\text {target }}^{\max } \cdot \beta_{\text {target }}[i][2]$

Eq. (A.36)

$\Delta T_{\text {air }}^{\text {underheat }}=\Delta T_{\text {target }}^{\min } \cdot \alpha_{\text {target }}[i][1]-\Delta T_{\text {target }}^{\min } \cdot \beta_{\text {target }}[i][1]$

Eq. (A.37) 


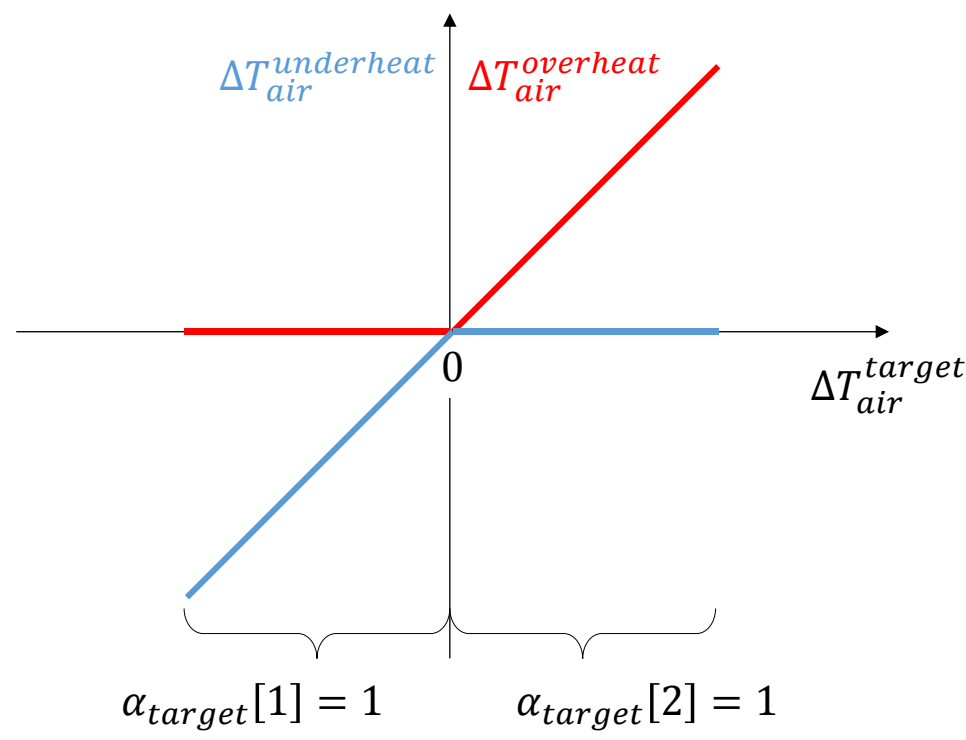

Figure 14. Representation of the linearization of Eqs. Eq. (16) and Eq. (17)

Bounds on decision variables:

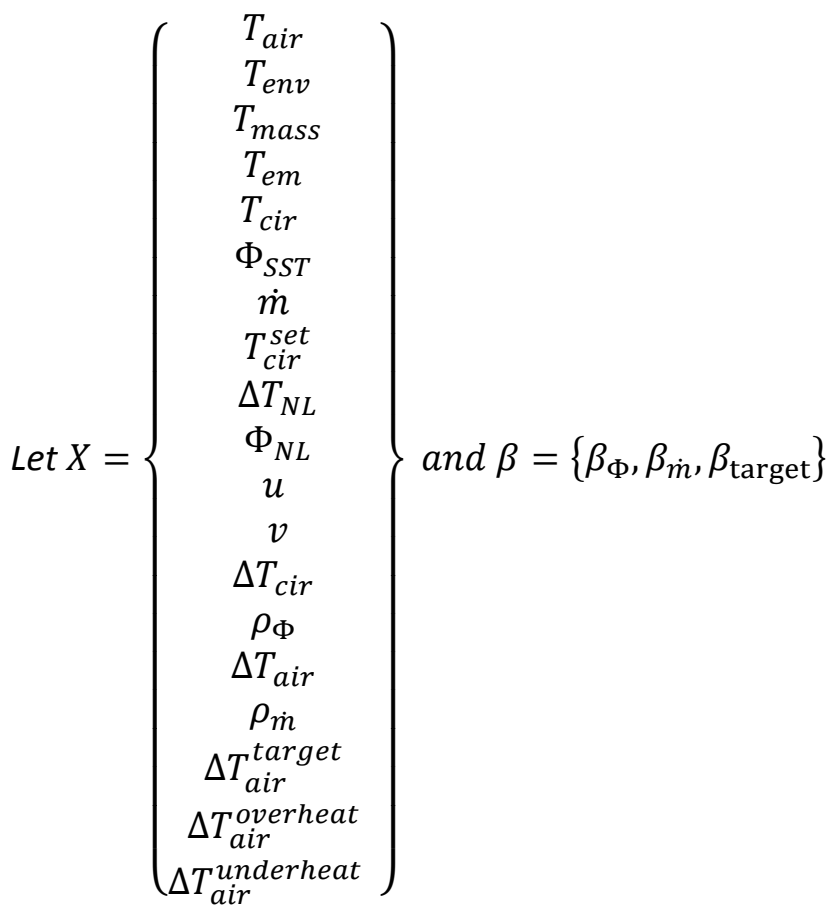

$X$ is bounded by physically acceptable values and $\beta$ is bounded between 0 and 1 :

$$
\begin{aligned}
& X^{\min } \leq X[i] \leq X^{\max } \\
& 0 \leq \beta[i] \leq 1
\end{aligned}
$$




\section{References}

[1] CEREMA, Chiffres-cles sur la consommation énergétique dans les bâtiments, (2013). http://reseaux-chaleur.cerema.fr/consommation-denergie-dans-les-batiments-chiffres-cles2013.

[2] ADEME, Chiffres-clés sur le climat, air et energie, (2014). https://www.ademe.fr/sites/default/files/assets/documents/chiffres-cles-climat-air-energie8705-bd.pdf.

[3] H. Lund, B. Möller, B.V. Mathiesen, A. Dyrelund, The role of district heating in future renewable energy systems, Energy. 35 (2010) 1381-1390. doi:10.1016/j.energy.2009.11.023.

[4] M. Münster, P.E. Morthorst, H.V. Larsen, L. Bregnbæk, J. Werling, H.H. Lindboe, H. Ravn, The role of district heating in the future Danish energy system, Energy. 48 (2012) 47-55. doi:10.1016/j.energy.2012.06.011.

[5] H. Lund, S. Werner, R. Wiltshire, S. Svendsen, J.E. Thorsen, F. Hvelplund, B.V. Mathiesen, 4th Generation District Heating (4GDH), Energy. 68 (2014) 1-11. doi:10.1016/j.energy.2014.02.089.

[6] S. Werner, District heating and cooling in Sweden, Energy. 126 (2017) 419-429. doi:10.1016/j.energy.2017.03.052.

[7] H. Lund, N. Duic, P.A. Østergaard, B.V. Mathiesen, Future district heating systems and technologies: On the role of smart energy systems and 4th generation district heating, Energy. 165 (2018) 614-619. doi:10.1016/j.energy.2018.09.115.

[8] S. Fazlollahi, N. Schüler, F. Maréchal, A solid thermal storage model for the optimization of buildings operation strategy, Energy. 88 (2015) 209-222. doi:10.1016/j.energy.2015.04.085.

[9] E. Guelpa, G. Barbero, A. Sciacovelli, V. Verda, Peak-shaving in district heating systems through optimal management of the thermal request of buildings, Energy. (2017). doi:10.1016/j.energy.2017.06.107.

[10] D.F. Dominković, P. Gianniou, M. Münster, A. Heller, C. Rode, Utilizing thermal building mass for storage in district heating systems: Combined building level simulations and system level optimization, Energy. 153 (2018) 949-966. doi:10.1016/j.energy.2018.04.093.

[11] P.-D. Moroşan, R. Bourdais, D. Dumur, J. Buisson, Building temperature regulation using a distributed model predictive control, Energy Build. 42 (2010) 1445-1452. doi:10.1016/j.enbuild.2010.03.014.

[12] F. Oldewurtel, A. Parisio, C.N. Jones, D. Gyalistras, M. Gwerder, V. Stauch, B. Lehmann, M. Morari, Use of model predictive control and weather forecasts for energy efficient building climate control, Energy Build. 45 (2012) 15-27. doi:10.1016/j.enbuild.2011.09.022.

[13] M.Y. Lamoudi, Distributed model predictive control for energy management in building, PhD Thesis, Université Grenoble Alpes, 2012. https://tel.archives-ouvertes.fr/tel00875593/document (accessed January 18, 2017).

[14] D. Sturzenegger, D. Gyalistras, M. Morari, R.S. Smith, Model Predictive Climate Control of a Swiss Office Building: Implementation, Results, and Cost-Benefit Analysis, IEEE Trans. Control Syst. Technol. 24 (2016) 1-12. doi:10.1109/TCST.2015.2415411. 
[15] R. De Coninck, L. Helsen, Practical implementation and evaluation of model predictive control for an office building in Brussels, Energy Build. 111 (2016) 290-298. doi:10.1016/j.enbuild.2015.11.014.

[16] S. Prívara, J. Široký, L. Ferkl, J. Cigler, Model predictive control of a building heating system: The first experience, Energy Build. 43 (2011) 564-572. doi:10.1016/j.enbuild.2010.10.022.

[17] F. Verrilli, S. Srinivasan, G. Gambino, M. Canelli, M. Himanka, V. Del, M. Sasso, L. Glielmo, Model Predictive Control-based optimal operations of district heating system with thermal energy storage and flexible loads, (2016). doi:10.1109/TASE.2016.2618948.

[18] M. Killian, M. Kozek, Ten questions concerning model predictive control for energy efficient buildings, Build. Environ. 105 (2016) 403-412. doi:10.1016/j.buildenv.2016.05.034.

[19] S. Prívara, J. Cigler, Z. Váňa, F. Oldewurtel, C. Sagerschnig, E. Žáčeková, Building modeling as a crucial part for building predictive control, Energy Build. 56 (2013) 8-22. doi:10.1016/j.enbuild.2012.10.024.

[20] A. Foucquier, S. Robert, F. Suard, L. Stéphan, A. Jay, State of the art in building modelling and energy performances prediction: A review, Renew. Sustain. Energy Rev. 23 (2013) 272-288. doi:10.1016/j.rser.2013.03.004.

[21] S. Prívara, Z. Váňa, E. Žáčeková, J. Cigler, Building modeling: Selection of the most appropriate model for predictive control, Energy Build. 55 (2012) 341-350. doi:10.1016/j.enbuild.2012.08.040.

[22] M. Wetter, W. Zuo, T.S. Nouidui, Modeling of heat transfer in rooms in the modelica "buildings" library, in: Proc. Build. Simul. 2011 12th Conf. Int. Build. Perform. Simul. Assoc., 2011: pp. 10961103. https://miami.pure.elsevier.com/en/publications/modeling-of-heat-transfer-in-rooms-inthe-modelica-buildings-libr (accessed January 21, 2019).

[23] J. Le Dréau, P. Heiselberg, Energy flexibility of residential buildings using short term heat storage in the thermal mass, Energy. 111 (2016) 991-1002. doi:10.1016/j.energy.2016.05.076.

[24] H. Wolisz, T.M. Kull, R. Streblow, D. Müller, The effect of furniture and floor covering upon dynamic thermal building simulations, in: 2015: pp. 2154-2159. doi:10.1016/j.egypro.2015.11.304.

[25] K.A. Antonopoulos, E.P. Koronaki, Effect of indoor mass on the time constant and thermal delay of buildings, Int. J. Energy Res. 24 (2000) 391-402. doi:10.1002/(SICI)1099114X(200004)24:5<391::AID-ER585>3.0.CO;2-L.

[26] H. Johra, P. Heiselberg, Influence of internal thermal mass on the indoor thermal dynamics and integration of phase change materials in furniture for building energy storage: A review, Renew. Sustain. Energy Rev. 69 (2017) 19-32. doi:10.1016/j.rser.2016.11.145.

[27] N. Aoun, R. Bavière, M. Vallée, A. Brun, G. Sandou, Dynamic simulation of residential buildings supporting the development of flexible control in district heating systems, in: 13th Int. Model. Conf., Regensburg, Germany, 2019.

[28] City-zen, City-zen Project, Cityzen-Smartcity. (2018). http://www.cityzen-smartcity.eu/.

[29] J. Vivian, A. Zarrella, G. Emmi, M. De Carli, An evaluation of the suitability of lumpedcapacitance models in calculating energy needs and thermal behaviour of buildings, Energy Build. 150 (2017) 447-465. doi:10.1016/j.enbuild.2017.06.021. 
[30] T. Berthou, P. Stabat, R. Salvazet, D. Marchio, Development and validation of a gray box model to predict thermal behavior of occupied office buildings, Energy Build. 74 (2014) 91-100. doi:10.1016/j.enbuild.2014.01.038.

[31] H. Harb, N. Boyanov, L. Hernandez, R. Streblow, D. Müller, Development and validation of greybox models for forecasting the thermal response of occupied buildings, Energy Build. 117 (2016) 199-207. doi:10.1016/j.enbuild.2016.02.021.

[32] P. Bacher, H. Madsen, Identifying suitable models for the heat dynamics of buildings, Energy Build. 43 (2011) 1511-1522. doi:10.1016/j.enbuild.2011.02.005.

[33] M. Wetter, GenOpt (R), Generic Optimization Program, User Manual, Version 3.1.1, Lawrence Berkeley National Laboratory: Berkeley, CA, USA, 2016. http://simulationresearch.Ibl.gov/GO/.

[34] N. Aoun, R. Bavière, M. Vallée, G. Sandou, Development and assessment of a reduced-order building model designed for model predictive control of space-heating demand in district heating systems, in: Wroclaw, Poland, 2019.

[35] L. Giraud, M. Merabet, R. Baviere, M. Vallée, Optimal control of district heating systems using dynamic simulation and mixed integer linear programming, in: Proc. 12th Int. Model. Conf. Prague Czech Repub. May 15-17 2017, Linköping University Electronic Press, 2017: pp. 141150.

[36] Q. Wu, H. Ren, W. Gao, J. Ren, Multi-objective optimization of a distributed energy network integrated with heating interchange, Energy. 109 (2016) 353-364.

[37] M. Leśko, W. Bujalski, K. Futyma, Operational optimization in district heating systems with the use of thermal energy storage, Energy. 165 (2018) 902-915. doi:10.1016/j.energy.2018.09.141.

[38] S. Fazlollahi, N. Schüler, F. Maréchal, A solid thermal storage model for the optimization of buildings operation strategy, Energy. 88 (2015) 209-222. doi:10.1016/j.energy.2015.04.085.

[39] M.J. Risbeck, C.T. Maravelias, J.B. Rawlings, R.D. Turney, A mixed-integer linear programming model for real-time cost optimization of building heating, ventilation, and air conditioning equipment, Energy Build. 142 (2017) 220-235.

[40] V. Kumtepeli, Y. Zhao, M. Naumann, A. Tripathi, Y. Wang, A. Jossen, H. Hesse, Design and analysis of an aging-aware energy management system for islanded grids using mixed-integer quadratic programming, Int. J. Energy Res. (2019).

[41] M. Killian, M. Zauner, M. Kozek, Comprehensive smart home energy management system using mixed-integer quadratic-programming, Appl. Energy. 222 (2018) 662-672.

[42] P. Vögelin, B. Koch, G. Georges, K. Boulouchos, Heuristic approach for the economic optimisation of combined heat and power (CHP) plants: Operating strategy, heat storage and power, Energy. 121 (2017) 66-77. doi:https://doi.org/10.1016/j.energy.2016.12.133.

[43] M. Vallée, R. Bavière, V. Seguin, V. Vuillerme, N. Lamaison, M. Descamps, A. Aurousseau, An efficient co-simulation and control approach to tackle complex multi-domain energetic systems: concepts and applications of the PEGASE tool, in: Wroclaw, Poland, 2019.

[44] FMI interface, Httpsfmi-Stand. (2019).

[45] G.P. McCormick, Computability of global solutions to factorable nonconvex programs: Part IConvex underestimating problems, Math. Program. 10 (1976) 147-175. 